\title{
Natural Killer Cells in the Malignant Niche of Multiple Myeloma
}

\author{
Ondrej Venglar 1,2,3, Julio Rodriguez Bago 2,3, Benjamin Motais ${ }^{1,2}$, \\ Roman Hajek ${ }^{2,3}$ and Tomas Jelinek ${ }^{2,3 *}$ \\ ${ }^{1}$ Faculty of Science, University of Ostrava, Ostrava, Czechia, ${ }^{2}$ Faculty of Medicine, University of Ostrava, Ostrava, Czechia, \\ ${ }^{3}$ Hematooncology Clinic, University Hospital Ostrava, Ostrava, Czechia
}

OPEN ACCESS

Edited by:

Fernando Guimaraes,

University of Queensland, Australia

Reviewed by:

Kyohei Nakamura,

The University of Queensland,

Australia

Karl-Johan Malmberg,

Oslo University Hospital, Norway

${ }^{*}$ Correspondence:

Tomas Jelinek

tomas.jelinek.md@gmail.com

Specialty section:

This article was submitted to

Cancer Immunity

and Immunotherapy,

a section of the journal

Frontiers in Immunology

Received: 16 November 2021

Accepted: 14 December 2021

Published: 11 January 2022

Citation:

Venglar O, Bago JR, Motais B, Hajek R and Jelinek $T$ (2022) Natural Killer Cells in the Malignant Niche of Multiple Myeloma.

Front. Immunol. 12:816499. doi: 10.3389/fimmu.2021.816499
Natural killer (NK) cells represent a subset of CD3- CD7+ CD56+/dim lymphocytes with cytotoxic and suppressor activity against virus-infected cells and cancer cells. The overall potential of NK cells has brought them to the spotlight of targeted immunotherapy in solid and hematological malignancies, including multiple myeloma (MM). Nonetheless, NK cells are subjected to a variety of cancer defense mechanisms, leading to impaired maturation, chemotaxis, target recognition, and killing. This review aims to summarize the available and most current knowledge about cancer-related impairment of NK cell function occurring in $\mathrm{MM}$.

Keywords: NK cells, multiple myeloma, inhibitory receptors, activating receptors, immunotherapy, microenvironment, niche

\section{INTRODUCTION}

Multiple myeloma (MM) is a malignant disorder of plasma cells (PCs) with a median age of 65 years at diagnosis. MM evolves from monoclonal gammopathy of undetermined significance (MGUS) present in $>3 \%$ of the population aged $>50$ years (1). The disease's clinical manifestations are mostly elevated serum calcium, renal failure, anemia, and bone involvement (the acronym CRAB) (2). Eventually, in up to $20 \%$ of cases, MM can progress into extramedullary disease (EMD), a soft tissue plasmacytoma, which represents a highly aggressive and treatment-resistant stage of MM (3-6). The mechanisms and biology of EMD are poorly understood, though PCs accumulate more chromosomal aberrations during EMD transformation (7).

Due to their natural tumor suppressor potential, natural killer (NK) cells became a subject of intensive research in cancer immunotherapy in both solid tumors and hematological malignancies $(8,9)$. Restoring or enhancing the effector abilities of NK cells for the treatment of MM has been one of the key topics in recent years (10-12). NK cell therapy is advantageous for several reasons: (1) NK cells are easy to isolate and expand in vitro using well-established methodologies; (2) these cells are capable of both direct killing and secretion of cytokines that can either potentiate other immune cells or suppress tumor cells; (3) overall biological features of NK cells are reducing the possibility of undesired side effects such as the ones observed with CAR-T cells; (4) NK cells are not antigen specific and there is no need for a specific target, although this can enhance the effectiveness of the therapy (13-15); and (5) the infusion of allogeneic NK cells is safe and does not cause the unwanted and deleterious graft vs. host disease (GvHD), thus opening the possibility of a more affordable offthe-shelf cancer cell-based immunotherapy (16).

Novel NK cell-based therapy possibilities include infusion of allogeneic/autologous NK cells, administration of in vitro expanded and genetically modified NK cells (including CAR-NK cells), 
cytokine-stimulated NK therapy, and monoclonal antibody (mAb)-based NK therapy $(13,15,17)$. Modification of inhibitory or activating surface molecules represent a promising option to potentiate efficacy of NK cells $(18,19)$. Another promising approach is priming of NK cells with certain interleukins (ILs). IL-2 and IL-15 supplementation in vitro was confirmed to enhance the NK cells' killing abilities, increasing the expression of activating NK cell receptors (20-22). Although the NK therapy seems to hold a huge potential for cancer therapy, a recent study showed that haploidentical NK cell transplantation in relapsed/refractory (RR) MM patients did not report significant therapeutic outcomes. The study had to be halted after all 12 patients relapsed within 90 days (23). Also, it is important to understand that $\mathrm{mAb}$ therapies for the treatment of MM act through (amongst others) NK-cell activities like antibody-dependent cell cytotoxicity (ADCC) mediated via either the mAb or mAb-drug conjugate (24-26). Anti-CD38 daratumumab (approved in 2015), anti-SLAMF7 elotuzumab (2015), and anti-CD38 isatuximab (2020) are mAbs used for the treatment of $\operatorname{MM}(25,27,28)$. The novel anti-CD38 MOR202 is now in the clinical trial phase in MM patients (29). Likewise, proteasome inhibitors and immunomodulating agents such as thalidomide, lenalidomide, and bortezomib have been proved to potentiate NK cell activity against MM (28).

Understanding the NK cell biology and mechanisms affecting the function of NK cells in MM is crucial for further progress in the field of targeted and NK cell therapy. This review summarizes the most recent and available data providing a necessary insight into the origin and development of NK cell subsets, their biology, antitumor abilities, and, mainly, impairment of function occurring in the MM microenvironment.

\section{NK CELL DEVELOPMENT AND SUBSETS}

NK cells represent $2-31 \%$ of peripheral blood (PB) lymphocytes (30). Although the organ and tissue distribution and circulation of NK cells are not fully understood, they are also present in the bone marrow (BM), liver, spleen, lungs, uterus, thymus, and secondary lymphoid tissues $(31,32)$. Maturation and differentiation of early NK subsets occurs in BM and secondary lymphoid organs. Even though NK cell development in humans is understood less than in mice, stages 1 to 6 were identified (8 overall with substages) in humans, each having a distinct immunophenotypic profile (Figure 1) $(33,34)$. Several ILs are crucial for the development of the NK lineage, mainly IL-2, IL-7, and IL-15, but also pro-inflammatory IL-12, IL-18, IL-27, and IL-35 $(35,36)$.

Similar to all other hematopoietic lineages, the NK lineage is derived from bone marrow-residing hematopoietic stem cells (HSCs), which transition into CD34+ CD45RA- CD133+ multipotent progenitor (MPP) cells and subsequently to CD34+ CD133+ CD45RA+ lymphoid-primed multipotent progenitors (LMPPs), determining the lymphoid line potential. Direct NK cell lineage precursors seem to be derived from the
CD34+ CD133+ CD45RA+ CD10+ fraction, known as common lymphoid progenitors (CLPs) in the conservative model of hematopoiesis, or multi-lymphoid progenitors (MLPs) according to the proposed hematopoietic tree revision. The revision does not distinguish NK lineage potential and further NK cell development since the study aimed at early CD34+ progenitors and also mainly on the revision of the general myeloid and lymphoid progenitor potential $(35,37,38)$. The earliest NK precursors with acknowledged NK lineage potential were identified as CD127+ in mice (39). This correlates with $\mathrm{CD} 34+\mathrm{CD} 133+\mathrm{CD} 45 \mathrm{RA}+\mathrm{CD} 7+\mathrm{CD} 117+\mathrm{CD} 127+$ stage 2a phenotype in humans. CD7 (from the stage 2a) and CD122 (from the stage $2 \mathrm{~b}$ ) are subsequently expressed throughout the whole NK cell lineage. Stage 3 represents a transitional stage between NK precursors and mature NK cells with a complete loss of CD34, CD133, and CD127 but with prevailed high levels of CD117 (35, 40-42). Mature subtypes of NK cells (stages 4a, 4b, 5 and 6), all with the characteristic CD3- CD7+ CD45RA+ CD56+/dim immunophenotype are characterized by the progressive loss of CD117 from high to low levels in stage 4 to stage 6 (the final stage) being completely CD117-, and with the gain of CD56 $(33,43,44)$.

CD56 and CD16 represent two of the most common and relevant markers used to identify NK cells $(32,45)$. For a proper flow cytometric detection of all mature NK cell subsets, both CD56 and CD16 should be included in the panel since CD16 is expressed only in stages 5 and 6, and CD56 alone is not sufficiently specific (32). CD3 should also be mandatory for correct NK cell evaluation to exclude CD3+ CD7+ CD56+ NK-like T cells (46). Based on the expression of CD56 and CD16, two main mature functional subsets are often described: CD56+/bright CD16-/dim and CD56dim CD16+/ bright (47). CD56+ CD16- cells (accounting for 5-10\% of circulating NK cells) are agranular with low cytotoxic activity and are considered mainly to be cytokine and chemokine producers. These cells co-express CD94/NKG2A in a high manner, meaning the CD56+ CD16- subset consist of both stages $4 \mathrm{a}$ and $4 \mathrm{~b}$. Contrary to this, CD56dim CD16+ cells (90\%-95\% of circulating NK cells) are designated as true killer cells with a high cytolytic potential against infected, tumortransformed, or otherwise immunocompromised cells due to the expression of CD16 (Fc $\gamma$ receptor III), which acts as a cell lysis signal transducer. A typical feature is the diminished expression of CD94/NKG2A compared to high levels of this antigen on the surface of CD56+ CD16- cells $(45,48-50)$.

CD57+ is a terminal marker of CD8+ T cells and also NK cells (51). The CD56dim CD16+ subset consists of developmental stages 5 and 6 . The main difference in these two stages is in the expression of CD57 and regulatory surface molecules known as the Killer cell Ig-like Receptors (KIRs); stage 5 lacks CD57 and maintain only low levels of KIRs (NK stage 5 immunophenotype: CD56dim CD16+ CD57- KIRdim), whereas the terminal stage 6 expresses both CD57 and KIRs in a high manner (NK stage 6 immunophenotype: CD56dim CD16+ CD57+ KIR+) $(32,35)$.

The CD56- CD16+ subset was also identified in high numbers in individuals with chronic infections (HIV and HCV). 


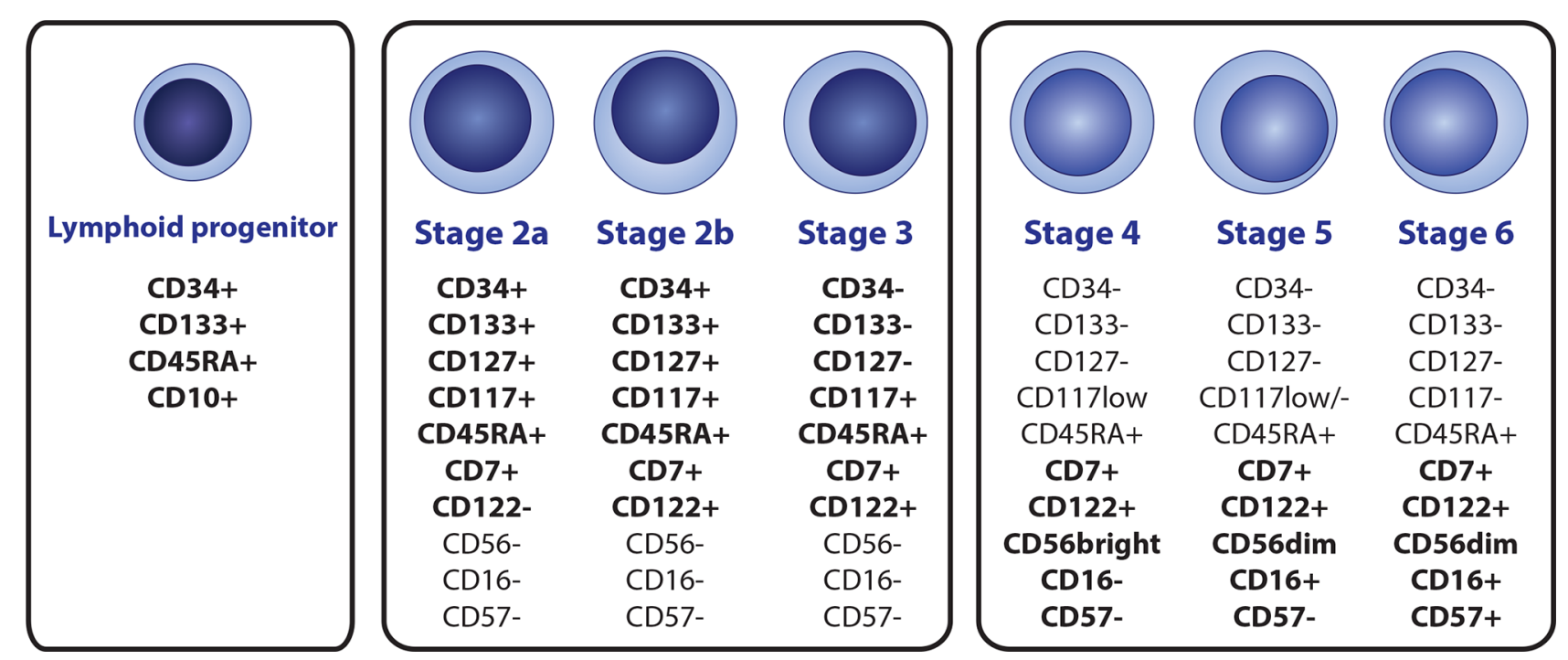

FIGURE 1 | A scheme of the NK cell development, with immunophenotypic profile of the most relevant markers that are suitable for identification of individual subsets by flow cytometry. NK cell lineage is derived from the CD34+ CD133+CD45RTA+CD10+ Iymphoid progenitor (terned also as a stage 1), Immature stages 2a, $2 \mathrm{~b}$ and 3 can be distinguished by the differential expression of CD34, CD122 and CD127, while high levels of CD117 are preserved. Mature stages 4 (4a $+4 b)$, 5, and 6 can be distinguished by diverse expression of CD16, CD56 and CD57.

The subset is described as dysfunctional, with higher expression of NK inhibitory receptors, lower levels of NK cytotoxic molecules, and both limited cytotoxic function and secretion of anti-inflammatory cytokines $(52,53)$. NK subsets can also be described by different levels of CD27 and CD11b in both mice and humans $(54,55)$.

Although there are several known and accurately described subsets of NK cells, it seems that diversity in the expression of different NK surface molecules pushes the variability of NK cells beyond the limits of standard flow cytometry. Between 6,000 and 30,000 different NK phenotypes can be detected in one individual and up to 100,000 in a group of individuals using the mass cytometry approach (56).

\section{NK CELL BIOLOGY IN ANTICANCER IMMUNITY}

The role of NK cells in anticancer surveillance is unquestionable in the modern era. Many studies have highlighted the significance of NK cells in the elimination of malignant cells or in cancer progression regulation, a topic that has been heavily reviewed in recent years $(49,57,58)$. NK cells were originally categorized as part of the innate immunity; however, memory and education abilities have been a matter of discussion lately (59). These cells lack specific antigen receptors compared to other lymphocyte subsets. The anti-cancer potential of NK cells is mediated either directly in a contact-dependent manner through their ability to induce programmed cell death, or indirectly in a contact-independent manner through the secretion of various cytokines, or in both manners by cooperation with other cells of the immune system (60). A broad spectrum of surface regulatory molecules is involved in NK regulatory actions (61).

\section{Anticancer Mechanisms of NK Cells}

The release of cytokines and chemokines, which are soluble, omnipresent, and crucial immune system regulators, is one of the key antitumor abilities of NK cells (48). The CD56+ CD16- NK cell subset is considered a major cytokine producer with low killing abilities (47). Nonetheless, CD56dim CD16+ cells, otherwise with a strong cytolytic potential and present in the majority in peripheral blood, also act as cytokine producers mainly in the initial immune response, which helps in mobilizing other immune cells (62). Tumor necrosis factor $\alpha$ (TNF- $\alpha$ ) and interferon $\gamma($ IFN- $\gamma$ ) are among the most potent antitumor cytokines, but the NK cell cytokine repertoire also includes immunoregulatory IL-5, IL-10, and IL-13; chemokines CCL2 (MCP-1), CCL3 (MIP-1 $\alpha$ ), CCL4 (MIP-1 $\beta$ ), and CCL5 (RANTES); and GM-CSF as well (63).

The ability to induce apoptosis of the target cell is a primary and well-known regulatory mechanism of NK cells. Apoptosis induced by NK cells can be mediated by degranulation, death receptors, or mAb-CD16 binding (60). The degranulation ability of NK cells was proved to be crucial in tumor and metastatic regulation (64). A specialized organelle called secretory lysosome, mainly containing perforin and granzyme granules, is involved in the highly coordinated and regulated process (65, 66). Death receptors are TNF superfamily receptors expressed on the surface of many cells (67). Death receptor ligands expressed by NK cells (such as Fas ligand, TNF, and TRAIL) bind specifically to the death receptor domains on the surface of target cells, resulting in a conformational change of the receptor, 
recruitment of the adaptor protein, and apoptosis $(65,68)$. ADCC represents one of the cancer immunotherapy-related killing mechanisms of NK cells. ADCC is facilitated after the binding of an IgG mAb Fab fragment to the target surface antigen on one side and $\mathrm{Fc}$ fragment to the $\mathrm{Fc} \gamma$ receptor III (CD16) of the effector cell on the other side, creating the effector cell-mAb-target cell link with subsequent engagement of cytotoxic pathways (69).

\section{Surface Effector Receptors}

NK cell surface activating and inhibitory molecules play a crucial role in the regulation of $\mathrm{NK}$ cell killing abilities, cytokine production, and all actions, in general. These receptors are able to detect specific stress signals and changes in expression patterns of surface molecules on cells and consequently regulate NK cell activity, which is a deeply balanced process $(61,70)$. During differentiation, NK cells undergo a complex series of educational interactions between major histocompatibility complex type I (MHC-I) molecules and NK surface inhibitory receptors. Thus, they are educated to selftolerate other healthy cells in the body $(71,72)$. Also, interactions between non-classical MHC and non-MHC molecules were described (73). The concept of induced tolerance and inhibition of NK cell activity by recognizing $\mathrm{MHC}$ is fundamental for the regulation of the anti-cancer response. During malignant transformation, a series of changes in gene expression occur in transforming cells, leading to the downregulation or upregulation in the expression of surface molecules (74). In this context, the most important is the diminution of surface MHC-I molecules, which tags transformed cells as a potential target for eliminating NK cellregulatory mechanisms $(75,76)$.

NKG2A/CD94 heterodimer (CD159a), LAG-3, and a fraction of the killer Ig-like receptor (KIR/CD158) family (inhibitory KIRs [KIR2DL, KIR3DL subgroups]) are categorized as specific MHC-I/HLA-I recognizing inhibitory NK cell receptors $(61,77,78)$. However, this does not necessarily mean that any cells lacking MHC-I are the target of NK cells. There are several other inhibitory and co-inhibitory NK cell molecules like the Siglec family (e.g., Siglec 7 and Siglec 9), Tactile (CD96), PD-1, TIGIT, CD112R, IL-1R8 and TIM-3 (Figure 2) (77, 79, 80).

Nevertheless, a "missing-self" signal is not enough for the activation of NK cells. Expression of stress-induced signals which stimulate the NK cell-activating receptors is crucial for activating NK cell response (81). Cellular stress activates a variety of DNAdamage response, senescence, and tumor-suppressor signaling pathways, which consequently lead to the expression of activating ligands that are recognized by NK cell activating receptors (82). Also, the synergistic action of multiple activating molecules is required for the activation of NK cells, except for CD16 and NKG2C, which are able to activate cell response on their own without any other co-stimulation $(19,83,84)$. Several MHC-dependent and MHC-independent molecules are categorized as NK cell activating receptors, including activating KIRs (KIR2DS and KIR3DS subgroups), NKG2D, NKG2C, natural cytotoxicity receptors (NCRs [NKp30, NKp44, and NKp46]), Nkp80 (not clearly categorized as NCR),
ICOS, DNAM-1 (CD226), CRTAM, and signaling lymphocyte activation molecule (SLAM) family members like 2B4 (CD244), CD48, Ly9 (CD229), NTB-A (CD352), and SLAMF7 (CD319) (Figure 3) (19, 85-92).

Originally, functional receptors of NK cells were categorized either as inhibitory or activating, but there are hints that the function of some molecules might be much more complex with a dual inhibitory and activating potential or at least a costimulatory function (13). For example, both the inhibitory and activating potential of 2B4 (CD244) was proved (93). There seems to be evidence that the activating molecule NKG2D also has broad costimulatory abilities of other activating receptors (94).

Other molecules are of course present on the surface of NK cells, but they are not clearly categorized among the activating or inhibitory receptors. Nevertheless, CD38, which is an important signal transducing, activating, and adhesion molecule, was also proved to activate NK cell effector response $(95,96)$. CD27, a Tcell co-stimulatory molecule, is not mentioned similarly in this context, but CD27 was connected with the enhanced cytotoxic activity of NK cells (97).

\section{MICROENVIRONMENT}

The BM niche, in general, is a deeply complex environment, which consists of cellular and noncellular components. The cellular compartment is represented either by hematopoietic cells, or nonhematopoietic cells such as mesenchymal stromal cells (MSCs), osteolineage cells, adipocytes, and endothelial cells. Cytokines, chemokines, growth factors, reactive species, extracellular matrix (ECM) proteins, and other molecules form the noncellular compartment $(98,99)$. BM function is negatively affected in hematological malignancies due to the tumor microenvironment (TME), which creates advantageous conditions for clonal cells and suppressive conditions for normal cells. In MM, disease manifestation, progression, and treatment resistance are often reflected with TME and its individual components $(100,101)$. Single-cell transcriptomics data revealed that alteration in the immune setup of the BM niche can be observed early from the MGUS stage, including increased frequency of NK cells, T cells, and monocytes. T cells exhibit accumulation of Treg and $\gamma \delta$ T-cell subsets at MGUS, accompanied by decrease of CD8+ memory subsets at the stage of SMM. Importantly, the patterns of immune dysregulation are heterogeneous in $\mathrm{MM}$ patients and might represent a possible indicator for the risk stratification (102).

\section{Non-Cellular Compartment}

The role of cytokines, growth factors, extracellular vesicles, and other molecules was described in the process of TME transformation and MM progression (103). Furthermore, the presence of tumorigenic molecules plays a critical role in the concept of pre-metastatic niche describing slow and remote TME orchestration, connected to the disease dissemination $(104,105)$. Malignant BM is highly inflammatory and hostile to nonmalignant cells (including NK cells), a fact that is reflected by 


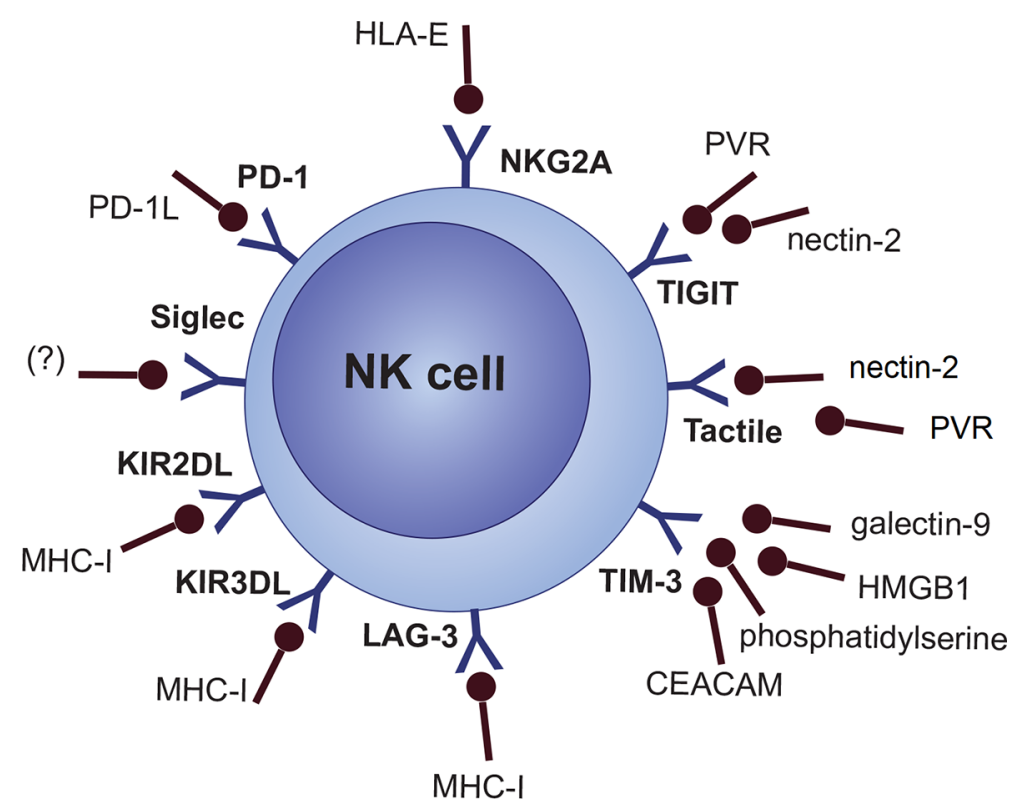

FIGURE 2 | NK cell inhibitory receptors will their cognate ligands.

elevated levels or altered expression of pro-inflammatory factors such as IL-1, IL-6, IL-10, IL-17, IL-18, IL-21, IFN- $\gamma$, TGF- $\beta$, TNF- $\alpha$, HGF, EGF, and HIF- $1 \alpha$; chemotactic factors recruiting other pro-inflammatory cells such as CCL2, CCL3, CCL4, CXCL12 (SDF-1), CSF-1, GM-CSF, and MSP; and proangiogenic factors supporting neovascularization such as VEGF, IGF-1, FGF, PDGF, reactive oxygen species (ROS), and reactive nitrogen species (RNS). The overall profile of soluble factors is a deeply complex topic itself (106-110).

\section{Cellular Compartment}

Normal cells present in the BM stroma can be clearly reprogrammed to support the disease manifestation and progression. This is reflected by the fact that immature BM MSCs have an abnormal genomic profile compared to their normal counterparts and provide advantageous environment for the expansion of MM cells $(111,112)$. Hence, the role of MSCs in disease persistence was suggested. Single-cell transcriptomic analysis revealed that MSCs in MM are highly proinflammatory, their transcriptomic profile can be tracked even post-treatment, and unfortunately, therapy is not effective in normalizing the BM niche. The study also revealed that MM MSCs are stimulated by pro-inflammatory cytokines that are most likely produced by immune cells such as IFN-responsive T cells and CD8+ memory T-cell subsets (113). MSCs development is also disrupted in $\mathrm{MM}$, and aberrancies were described in more mature osteolineage cells and adipocytes $(114,115)$. The differentiation of MSCs is shifted preferentially towards the adipocyte lineage in MM, and, if the high secretory potential of adipocytes is taken into consideration, this may favor further disease progression as well (116). EPHB1, FBLN5, RELL1, ADAMTS17 are among the impaired genes in MM-affected MSCs.
Downregulation of $B M P 10$, the bone morphogenic protein 10 gene, in MM MSCs reflects the impaired osteoblastic differentiation, and it seems that BMP signaling is involved in MM bone disease progression. Therefore, inhibition of the BMP axis, as well as others such as TGF $\beta$, Notch, Wnt, or Runx2/Cbfa1 signaling, represents a possible option for therapy improvement in MM (112, 117, 118). Interestingly, interactions between MM cells and BM MSCs trigger the production of IL- 6 and a number of cytokines and chemokines, including TNF- $\alpha$, VEGF, IGF-1, CXCL12, IL-1 $\beta$, TGF- $\beta$, CCL-3, and CCL 4 with immunomodulatory activity $(119,120)$.

Over-angiogenic potential of endothelial cells (ECs) was linked with neovascularization and disease progression in MM (121). ECs of MM patients also have a distinctive genetic profile that strongly supports their neoangiogenic potential. Genes involved in neovascularization, such as $b F G F, F G F-7, V E G F-A, V E G F-B$, $V E G F-C, V E G F-D$, and GRO $\alpha$, together with ETS-1, HIF- $1 \alpha$, ID3, and osteospontin transcription factors, are overexpressed in MM ECs (122). Also, filamin A, vimentin, and $\alpha$-crystallin B proteins are overexpressed by MM ECs, though anti-MM drugs such as bortezomib and lenalidomide affect these proteins during treatment (123). The hypoxic niche and HIF-1 $\alpha$ overexpression are key factors in MM neovascularization as well (124).

The most relevant hematopoietic cells contributing to the MM TME are without a doubt malignant PCs, macrophages, myeloid-derived suppressor cells (MDSCs), and T-regulatory lymphocytes (Tregs) (105). Overall impact of malignant PCs can be seen throughout the whole chapter, but briefly, the role of PCs in the organism is much more complex than just antibody production. They are able to produce many soluble factors, including IL-1, IL-10, IL-12, IL-17, IL-35, TNF- $\alpha$, TGF- $\beta$, and GM-CSF, which indicate their role in immune and 


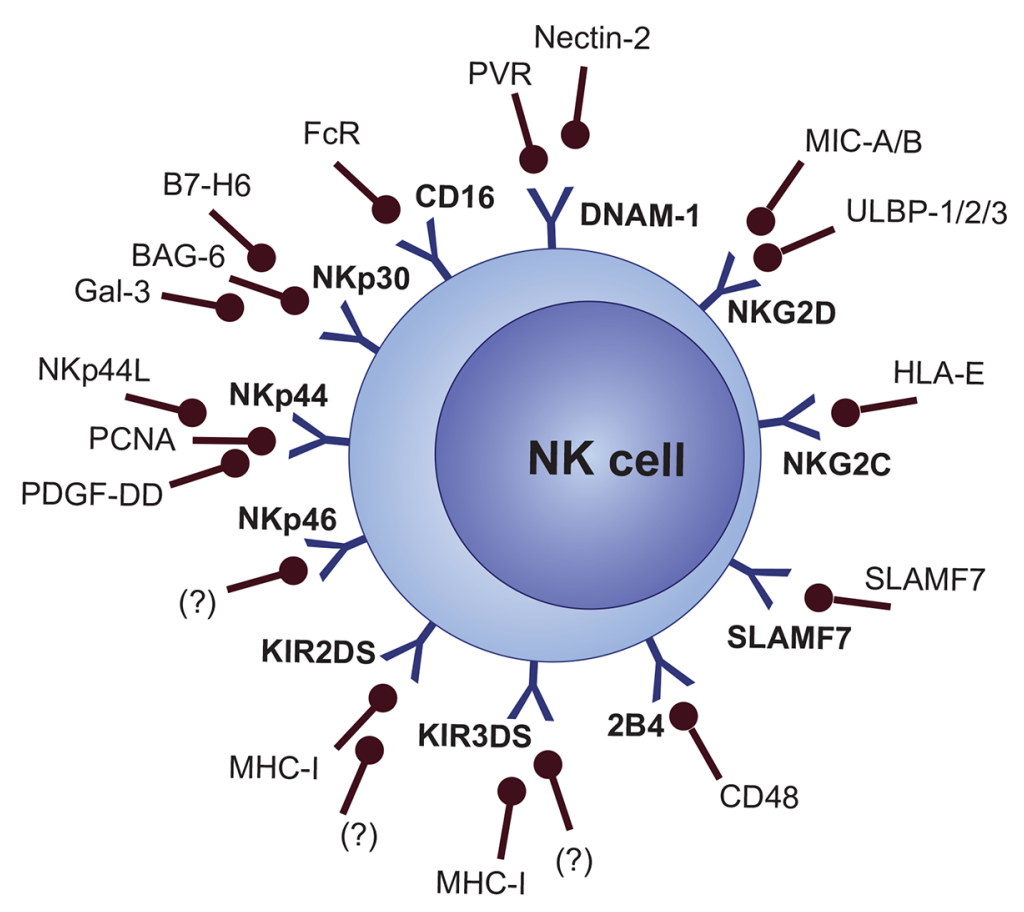

FIGURE 3 | NK cell activating receptors and their ligands.

hematopoietic modulation (125-127). Over 400 genes are deregulated in MM PCs compared to normal PCs, which could reflect their ability to alter the niche to favor myeloma progression (128).

Macrophages, in the context of the malignant niche, are divided into two groups: classically activated M1 macrophages, and alternatively activated M2 macrophages. The function and phenotype of macrophages depends on their microenvironment, and the general term "tumor associated macrophages" (TAMs) is used to distinguish these cells from normal macrophages (though M2 cells are sometimes classified as TAMs) (129). M1 cells are pro-inflammatory, anti-tumor macrophages activated by bacterial lipopolysaccharides or cytokines produced by Th- 1 lymphocytes and secrete IL-1 $\beta$, IL-6, IL-12, IL-23, TNF- $\alpha$, ROS, and RNS. M2 macrophages are activated in response to factors produced by Th2 lymphocytes, such as IL-4, IL-10, IL-14, and glucocorticoids. These cells are considered tumorigenic, immunosuppressive and, among others, they produce IL-10, TGF- $\beta$, VEGF, matrix metalloproteinases (MMPs), and ARG-1 (109). A high frequency of TAMs was associated with worse prognosis and treatment resistance in MM (130). It was also proved that TAMs cooperate with other cells in the niche. They can mimic ECs in MM and promote neovascularization through VEGF and FGF-2 stimulation (131). Macrophage chemotaxis towards MM BM niche and shift to the tumorigenic M2 phenotype is mediated via CCL2, CCL3, CCL14, CXCL12, CSF-1, GM-CSF, MSP, PDGF, and TGF- $\beta$, which are produced by MM-associated MSCs (109).

MDSCs were confirmed as immune system inhibitors in cancer patients. These cells express typical CD33+ CD11b+
HLA-DR-/low immunophenotype, with further subdivision into CD15+ granulocytic (G-MDSCs) or CD14+ monocytic (M-MDSCs) subsets (132). It was proposed that G-MDSCs differentiate into tumor-associated neutrophils (TANs) and, similarly, that M-MDSCs are precursors of TAMs. However, possible polarization of normal neutrophils into TANs in the TME is also discussed (133). Increased frequency of MDSCs was found in MM patients, which was also correlated with disease progression and therapy outcome $(134,135)$. MDSCs produce ROS, RNS, and ARG1, which in detail impair the function of the CD3 T-cell co-receptor participating in the activation of both CD4+ and CD8+ T-cells. Also, MDSCs downregulate the expression of $\mathrm{L}$-selectin (CD62L), thus decreasing $\mathrm{T}$-cell trafficking to the malignant niche $(133,136,137)$. Overall, an inhibitory role of MDSCs on the function of NK cells was proved by the co-culture of NK cells with MDSCs, which resulted in the downregulation of activating receptors, decreased secretion of IFN- $\gamma$, and decreased degranulation (138). Furthermore, data suggesting a pro-angiogenic potential of MDSCs in MM were published (139). RNS and membrane-bound TGF- $\beta$ are among the MDSC-derived factors inhibiting NK cell function $(140,141)$. Overall cooperation of cells present in the malignant niche is reflected by a confirmed ability of MM MSCs to induce the upregulation of TNF $\alpha, A R G 1$, and pro-angiogenic PROK2 in MDSCs (135).

CD3+CD4+CD25+ Tregs are important modulators of normal immune response. The role of Tregs in MM progression seems to be a matter of discussion due to contradictory data. Both decreased and increased Treg frequency can be detected in MM. Increased Tregs were 
associated with the disease progression, but contradictory data are published too. Nevertheless, these cells clearly contribute to dysfunctional immunity in $\mathrm{MM}$, though the role seems to be heterogeneous (142-146). IL-10 and TGF $\beta$ are probably the most discussed cytokines produced by Tregs that may contribute to pathological features of MM BM (144). One of the key Treg-related aspects to maintain functional immunity in $\mathrm{MM}$ and tumors in general is a balance in the Treg vs. CD4+ Thelper 17 (Th17) cell ratio. Th17 cells contribute to the development and progression of chronic immune diseases, and cancer, by overall immune regulation and production of IFN- $\gamma$, TNF- $\alpha$, IL-10, IL-17, IL-21, IL-22, and IL-26. It seems that the Treg/Th17 differentiation axis is skewed in MM by elevated levels of IL- 6 and TGF $\beta$. In the presence of TGF $\beta$ alone, naive T cells that express Foxp 3 and differentiate into Tregs Th17 cells are generated in the combination of TGF- $\beta$ and IL- 6 , or IL-21 (146). Again, contradictory data have been published on the topic of the Treg/Th17 cell relationship to MM prognosis, and further clarification is needed. Nonetheless, Th17 cells produce high levels of IL-17, which was proved to promote growth of MM cells in vitro and in vivo $(147,148)$.

Without a doubt, MM niche is a deeply complex environment contributing to disease progression and persistence through modulation of the immune response. Nevertheless, only limited data are published about how individual components affect the function of NK cells, which will be discussed in the next chapter.

\section{NK CELLS IN THE MYELOMA NICHE}

NK cells act as important regulators in the development and progression of hematological malignancies and their suppressor activity particularly against $\mathrm{MM}$ cells was confirmed in many studies (149-152). Nonetheless, significant changes in the distribution of NK subsets and dysfunctions of NK cells were described in MM patients $(153,154)$. The functional activity of NK cells was also correlated with disease staging (155). Recent studies provided an insight into mechanisms involved in the NK cell -mediated killing of malignant PCs and highlighted the role of interactions between surface effector receptors on the surface of NK cells and specific ligands $(156,157)$. The recognition of MM cells with activating receptors, including NKG2D, NKp46, and DNAM1 , has been proved (158). Also, a low expression of HLA-1 molecules on malignant PCs and the role of NK inhibitory receptor suppression was demonstrated in MM (150). Downregulation or upregulation of these surface molecules was associated with severe dysfunctions of NK cells in MM. However, details about involved mechanisms between NK cells and individual TME components remain poorly described (Figure 4) $(159,160)$ Data describing the NK cell distribution or functional capabilities in EMD lesions are missing completely, even though NK cell infiltration was connected with better overall survival in solid tumors (161).

\section{Impairment of NK Cell Development}

Since malignant populations are considered to be competitive to non-malignant cells, bone marrow brings a unique insight into the effect of myeloma on the development of healthy immune cells (100). In hematological malignancies, cancer niche disrupts normal hematopoiesis and results in a favorable environment for clonal cells (162). Several publications describe that overall lower percentage of circulating NK cells can be detected in the peripheral blood of MM patients in advanced disease stages with poor prognosis compared to controls, MGUS, and MM with good prognosis $(163,164)$. However, Pazina et al. recently published that frequencies of NK cells in $\mathrm{PB}$ of ND MM and smoldering multiple myeloma (SMM) patients are not significantly decreased compared to healthy donors (HD). Furthermore, overall numbers of PB NK cells in RR MM and post-stem cell transplant (post-SCT) patients were increased in this study, with CD56bright CD16- CD57- stage 4 subset prevailing. This was argued as a possible effect of NK lineage reconstitution after the disease and therapy depletion; hence, it might not reflect the actual disease impact. Frequencies of total NK cells in BM reflected the frequencies in PB, except post-SCT where the frequency was significantly lower in BM. Also, numbers of CD56dim CD57+ cells (representing the terminal and highly active stage 6) are lower in BM compared to $\mathrm{PB}$ of ND, RR, and post-SCT MM patients (165). To point out the importance of the terminal stage NK cells, MM patients with higher absolute numbers of CD57+ NK cells were associated with better prognosis compared to patients with higher numbers of more immature CD56bright CD16- CD57- cells (159). Similar to what was published by Pazina et al., overall NK cell numbers and cytotoxic abilities are reduced in B/T-ALL patients as a result of CD56bright CD16- cytokine-producing stage 4 accumulation. In this study, high numbers of cytokine CD56bright CD16- cells were also associated with poor prognosis (166). The accumulation of CD56bright CD16- subset and lower total frequencies of $\mathrm{NK}$ cells in the BM reflect that NK cell lineage differentiation is impaired during the progression of hematological malignancies. Nevertheless, scarce information is available in the context of altered NK cell maturation in the environment of malignant BM in general. No study so far has provided detailed data about NK progenitor subset distribution in leukemic or myeloma marrow $(167,168)$.

In general, early CD34+ CD38- HSCs are not depleted in leukemic marrow since they enter a self-protective quiescence. Nonetheless, leukemic niche affects hematopoietic differentiation leading to reduced levels of CD34+ CD38+ progenitors and subsequent cytopenias $(162,169)$. There is also evidence that NK maturation in BM is blocked in solid tumors, even though no direct contact is needed between tumor cells and NK cells. One of the reasons is most likely a remotely orchestrated IL-15R downregulation in cancer-altered BM stroma (170). The IL-15/ IL-15R axis is indeed an important NK cell development regulator and proliferation inducer, acting via IL-2R $\beta$ (CD122), and JAK/ STAT, Ras/MEK/MAPK, or PI3K/AKT pathways $(171,172)$. Mutations in GATA2 (absent CD56bright cells), MCM4 (absent CD56dim cells), IL2-R, JAK3, STAT5, and IL-15R were associated with impaired NK maturation $(44,173,174)$.

One of the possible suppressors of IL-15 signaling is prostaglandin E2 (PGE2), which downregulates the $\gamma$-chain of 


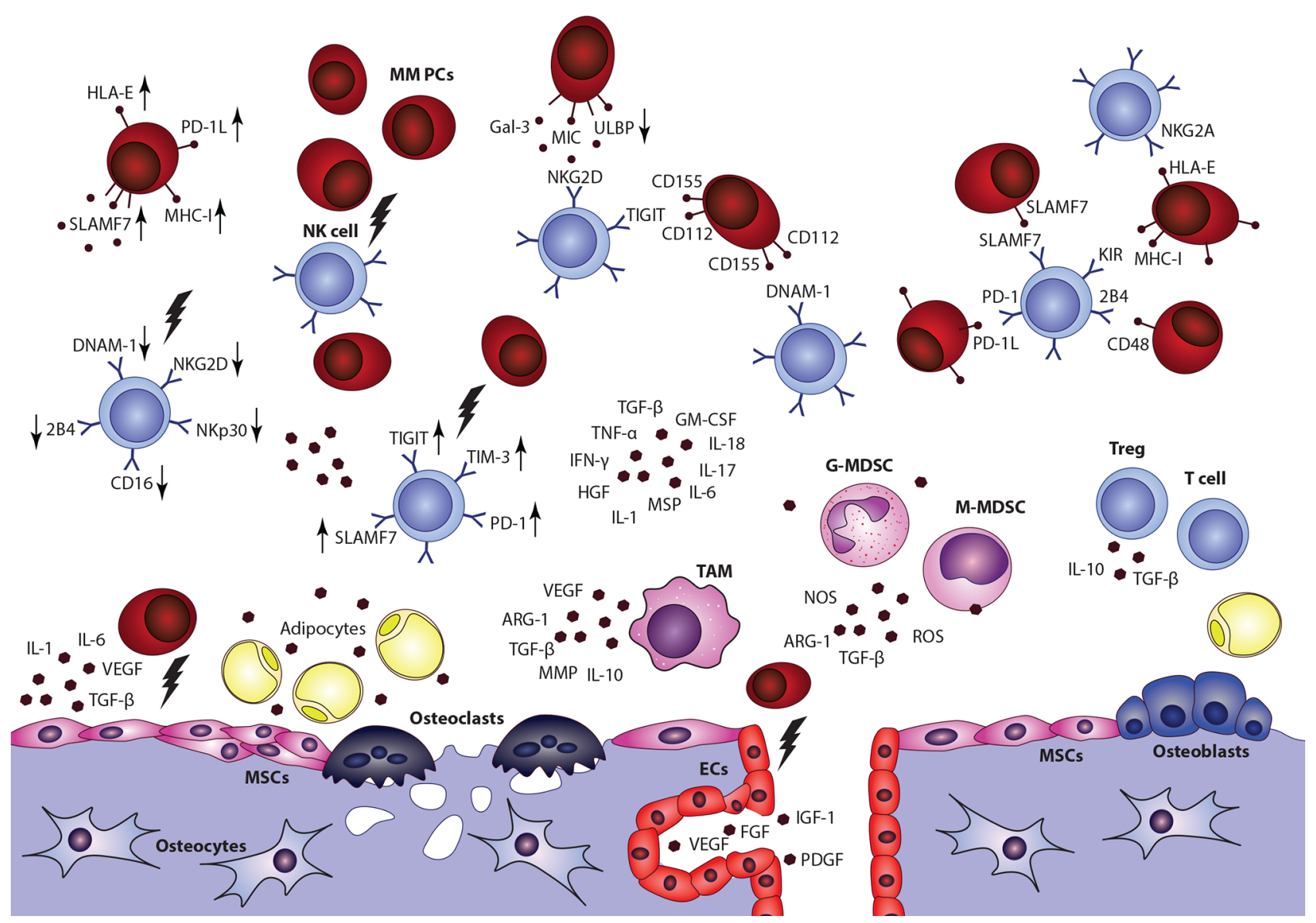

FIGURE 4 | Impact of multiple myeloma bone marrow microenvironment on the overall NK cell function is a complex topic, with only limited data available. Overall decrease of NK cells frequency, accumulation of CD56bright CD16-cytokine producing subset, impaired overall fuctional properties, and alterations of surface effector receptors were connected with the disease and its progression. Nonetheless, detailed data describing interactions between NK cells and individual components in the niche are incomplete. MSCs, mesenchymal stromal cells; ECs, endothelial cells; G-MDSC, granulocytic myeloid-derived suppressor cell; M-MDSC, monocytic myeloid-derived suppressor cell; TAM, tumor associated macrophage.

the IL-15R complex and subsequently inhibits NK cell function (175). Another candidate is ADAM17, which is activated through the IL-15 axis and reduces NK cell proliferation. Blockade of this metalloproteinase results in increased levels of L-selectin (CD62L) on NK cells, thus supporting the homing of these cells (176). However, not only downregulation of the IL15R function, but also chronic exposure to IL-15 leads to the NK cell exhaustion (177). Without a doubt, impaired IL-15R/IL-2R signaling and distorted NK cell maturation contributes to the disease progression. Levels of soluble IL-2R in serum and surface expression of IL-2R on malignant PCs or mononuclear cells are significantly increased in MM, which also correlates with the active state of the disease $(178,179)$. Quite unexpectedly, defects related to the IL-21 axis affect NK cell lytic abilities but not the maturation, even though IL-21 promotes NK cell differentiation (180-182). The maturation capacity of NK cells, together with their ability to respond to the presence of malignant cells, is also reduced with age as the BM stroma deteriorates with time, thus the age of the patients may play a crucial role in this context (183).

The inhibitory role of Tregs in the NK cell differentiation was also confirmed both in vitro and in vivo. Presence of activated Tregs in the culture of HSCs, which were expanded with NK cell lineage differentiation protocol, led to $90 \%$ reduction in $\mathrm{NK}$ numbers compared to the control. Similar inhibitory role of Tregs was observed also in mice (184). This phenomenon seems to be caused by increased levels of membrane-bound TGF- $\beta$ and active TGF- $\beta$ signaling $(184,185)$.

Finally, the low numbers of NK cells represent a major issue not only from the view of disease control and progression, but it should also be noted that cancer patients are more susceptible to infections, which are one of the main causes of mortality in MM $(186,187)$. Understanding the maturation distortion and recovering the generation of mature NK subsets could be crucial for the therapy outcome and patient survival improvement. 


\section{Impairment of NK Cell Localization and Chemotaxis}

TME-related downregulation or upregulation of chemotactic factors or their receptors is deeply beneficial for tumor growth, either to attract inflammatory or tumorigenic cells like MDSCs and TAMs, or to repel immunosuppressive cells. As already mentioned, it was well described that tumor infiltration by NK cells contributes to better prognosis. Thus, in hematological malignancies, it is only logical to expect the impairment of NK cell BM localization with consequent efflux to PB $(161,188)$. In general, several chemotactic receptors are expressed by NK cells, including CCR1, CCR2, CCR5, CCR7, CXCR1, CXCR3, CXCR4, CXCR6, CX3CR1, S1P5, CCRL2, and ChemR23. Indeed, aberrancies in these receptors were connected to lower NK cells' recruitment to the tumor (189).

CXCR4 is one of the key regulators of NK cell BM localization, and it is expressed in high levels by NK progenitors. With decreasing CXCR4 expression in mature stages, levels of CXCR3, CCR1, and CX3CR1 increase, whereas reduced CXCR4 expression, together with S1P5 activation, is necessary for NK cells to exit to the periphery and vice versa (190-192). In general, dysregulation in the CXCR3 and CXCR4 axes was connected to defective BM localization of NK cells in BM. Both of these pathways are closely connected. CXCR3 triggering possibly counteracts CXCR4-mediated BM retention by limiting the CXCR4 responsiveness. Only limited data are available about NK cell disrupted chemotaxis, BM localization and retention in $\mathrm{MM}$, or in other hematological malignancies. In MM BM, several chemokine ligands engaging in NK cell BM localization show a disbalance, including increased levels of CXCL9 and CXCL10 (CXCR3 ligands) and decreased levels of CXCL12 (CXCR4 ligand) (Figure 5). Levels of CCL3, CCL5, and CX3CL1 ligands are most likely not subjected to any changes (193).

In other cancers, CXCL12 was confirmed to be downregulated, together with CXCR2 reduction on the surface of NK cells, though data suggest that these changes occur on the post-translational level (194). Another study revealed that tumor tissues tend to overexpress CXCL3 and CXCL5, while expression of CXCL1, CXCL2, and CXCL7 decreases (195). There are also hints, that deregulated CXCR3 signaling in malignant PCs could play a role in MM to EMD progression, although this needs to be confirmed (196). Also, IFN- $\gamma$-mediated CXCR3 activation was associated with lower overall survival, and it was proposed as an independent prognostic factor in MM (197). Indeed, inhibition of the CXCR3 axis resulted in better efficacy of IL-15 activated NK cells against malignant PCs (198). CXCR4 was proved to be downregulated in metastatic cells, which also demonstrates its role in malignancy dissemination (199).

Besides, it seems that obstructions in NK cell chemokine signaling and $\mathrm{BM} / \mathrm{PB}$ localization are connected to the altered NK cell development and the prognosis-related CD56bright CD16- subset accumulation (as discussed previously). About $10 \%-20 \%$ of BM NK cells are localized in proximity to CXCL12 producing osteoblasts and reticular cells that are also able to express IL-15 and IL-15R. This localization is also dependent on the integrin chain $\alpha 4$ (200). Moreover, it was proved that the CXCR4/CXCL12 axis is essential for NK cell development in mice (201).

Chemokine signaling also actively participates in the recruitment of immune suppressor cells. CCR2 and CCR5 contribute to the migration of TAMs and MDSCs into the TME, whereas Tregs with higher expression of CXCR4 are attracted to the TME by their ligands CCL17 and CCL22, which can be produced by TAMs and cancer cells themselves (202). Further research is necessary to understand the chemokine ligand/receptor interactions between NK cells and TME. For example, studies evaluating chemokine/ligand expression profiles on MM cells and NK cell subsets in both BM and PB would probably uncover striking details regarding the role of chemokines in NK cell development and functional impairment, as well as MM-to-EMD progression.

\section{NK Cell Inhibitory Receptors in MM}

Blockade of the checkpoint axis PD-1/PD-1 ligand (PD-1/ $\mathrm{PD}-1 \mathrm{~L}$ ) involved in the inhibition of the immune response has been discussed lately, although this therapy alone seems to be ineffective in $\mathrm{MM}$ and combination with other treatment approaches is necessary (203-205). In cancer, expression of PD-1L1 by tumor cells is considered an evasion mechanism promoting the suppression of immune cells (206). Malignant PCs in MM were shown to express higher levels of PD-1L compared to HD or MGUS patients, and significant upregulation can be observed in RR MM patients. Also, PD-1L expression on malignant PCs was connected with resistance to anti-myeloma agents, and the expression of this ligand on PCs was proposed as a marker of poor prognosis in combination with other factors such as age and cytogenetics $(205,207,208)$.

Expression of PD-1 was confirmed on the surface of NK cells in MM while undetectable on healthy NK cells $(209,210)$. Indeed, it was proved that $\mathrm{PD}-1 / \mathrm{PD}-1 \mathrm{~L}$ negatively regulates NK function. However, in this study, at least low levels of PD1 were also detected on normal circulating or resting NK cells (211). To highlight the therapeutic potential, one study showed that inhibition of PD1/PD-1L signaling in NK cells can increase the degranulation or cytokine-producing ability in vitro (212). Of note, the data reflect the importance of a cautious approach during the flow cytometric detection of PD-1 and subsequent data evaluation since studies reported variable (low or none) levels of PD-1 on healthy NK cells. Furthermore, Pazina et al. encountered difficulties in the detection of any levels of PD-1 even in myeloma samples (165). A recent study proved that PD-1 mRNA and cytoplasmic PD-1 protein can be detected in NK cells, which suggests that surface PD-1 expression is inducible; hence, flow cytometry may provide variable data (213). There are data indicating the ominous role of the TME cellular compartment in PD-1/PD-L axis-related impairment of NK cells. PD-1L-positive MDSCs are present in higher frequency in cancer patients $(214,215)$. Furthermore, PD-1L expression in MM cells can be also induced by BM MSCs-derived IL-6, with subsequent engagement of JAK/TAT and MEK signaling (208, 216). Use of the JAK inhibitors (ruxolitinib) in MM truly 


\section{Bone marrow}

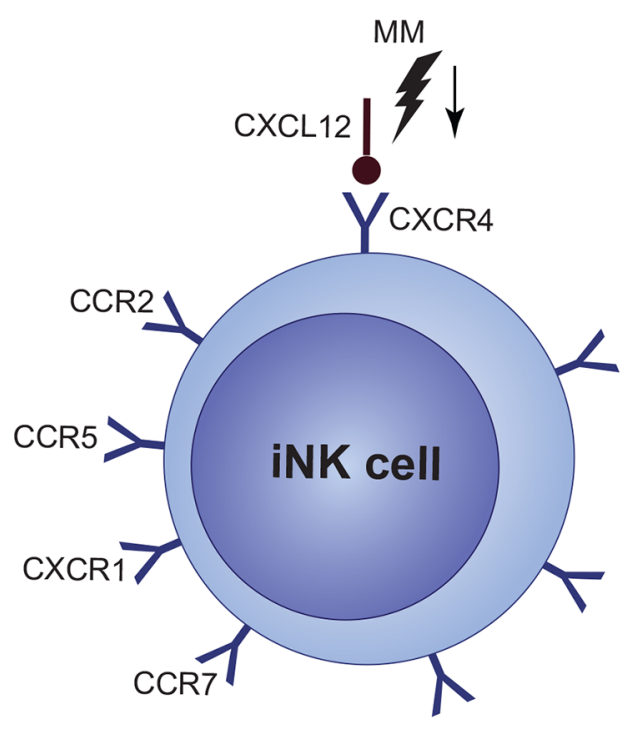

Peripheral blood

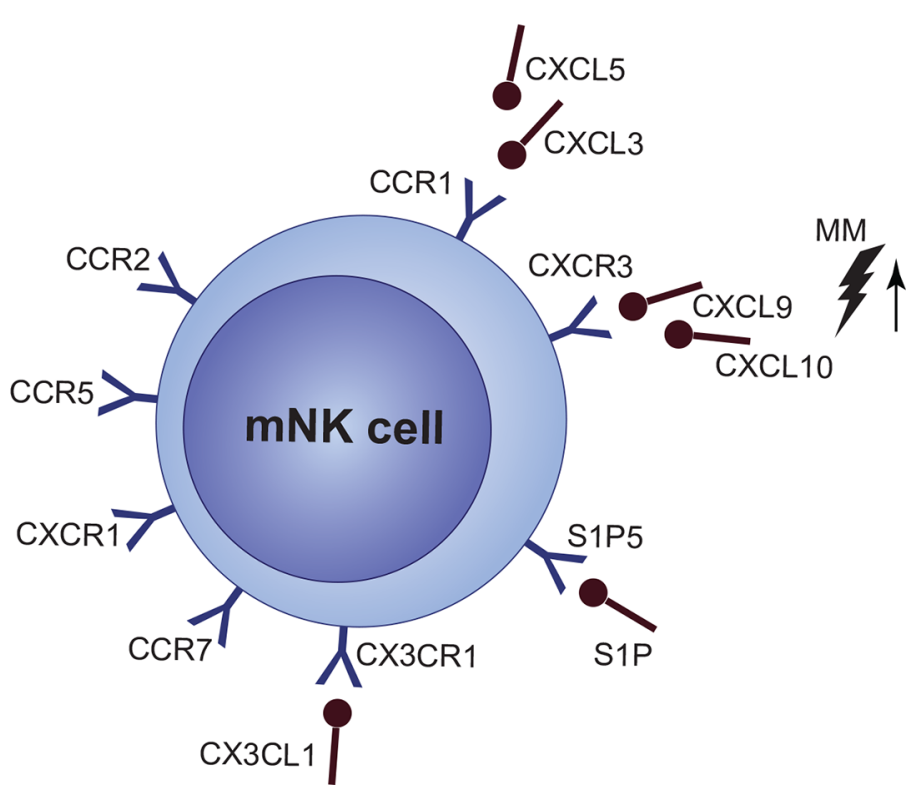

FIGURE 5 | Under normal conditions, immature NK cell (iNK cell) retention in the bone marrow (BM) is mediated via a high expression of CXCR4/CXCL12. Mature NK cells (mNK cell) express only low levels of CXCR4 and high levels of CCR1, CXCR3, CX3CL1 and S1P5 which mediate migration to the periphery. However, expression of individual chemokine receptors, or their ligands, as well as overall function of a crucial CXCR4/CXCR3 signaling, is impaired in multiple myeloma (MM). Occurring CXCL12 upregulation, together with CXCL9 and CXCL10 upregulation during the disease progression suggest, that NK cells are forced out of the BM by factors present in the MM niche. Furthermore, CXCR4/CXCR3 axes seems to be also crucial for the NK cell lineage development.

downregulates PD-1L expression in malignant PCs and makes them more susceptible to lenalidomide and steroids (217). Quite curiously, TGF- $\beta$, which is abundantly present in the MM niche, seems to have no effect on the expression of PD1-L1 and PD-L2 (218). However, other factors like IL-2, IL-7, and IL-15 were proved to upregulate levels of PD-1L (219). IL-2, IL-7, IL-15, IL18 , and IL-21 are able to upregulate the expression of surface PD-1 too, while IFN- $\alpha$ promotes the transcription of PD-1 (220, 221). HIF- $1 \alpha$ is also directly involved in the PD-1L upregulation, which, together with the inhibitory role of HIF-1 $\alpha$ in NK cells, propose a multilevel role of hypoxia in MM progression (222, 223).

CD94/NKG2A is an HLA-E-binding molecule recognized as an immune checkpoint like PD-1. Expression of this inhibitory receptor is increased in cancer-associated NK cells, which contributes to their exhaustion (224). Interestingly, HLA-E overexpression in tumors was connected to both poor and good prognosis $(225,226)$ Although there are data suggesting that the expression of NKG2A is not detrimental for the antiMM activity of in vitro activated NK cells, NKG2A is still a valid target for consideration in immunotherapy. High levels of HLA$\mathrm{E}$ in high-risk $\mathrm{MM}$ were proposed as a potential therapeutic candidate, and the experimental blocking of NKG2A by antibodies resulted in restored antitumor activity of NK cells (227-230). Among the MM niche factors, IFN- $\gamma$ was proved to be involved in cancer-related HLA-E overexpression (231).
Furthermore, HLA-E may serve to protect TAMs from CD94/ NKG2A-mediated cell lysis (232). From the receptor point of view, TGF- $\beta$ and IL-10 are among factors inducing the expression of NKG2A $(224,233)$. Also, IL-2 and IL-15 were shown to upregulate the expression of NKG2A, as well as NCRs, NKG2D, DNAM-1, and KIR2DL4 (234).

KIRs are crucial inhibitory regulators of NK cell response acting through interactions with MHC-I molecules, as already described. Tumor cells can temporarily upregulate their surface MHC-I expression to evade NK cell lysis. On the other hand, MHC-I downregulation is also a common mechanism to avoid immune response $(235,236)$. Masking the pathological origin (i.e., hiding the "missing-self" signal) by upregulating MHC-I levels is also a feature of MM PCs $(237,238)$. Moreover, increased levels of KIR molecules KIR2DL1 and KIR2DL2 were described on the PB NK cells of MM patients; however, no further details are available about involved mechanisms (61). Two strategies were proposed to exploit the KIR signaling for the therapy (239). The first is represented by HLA/KIR ligand-mismatched transplantation that showed promising results. Healthy donor NK cells provided a better response than NK cells of the patient, which are corrupted by the tumor inhibitory niche $(240,241)$. The second option is to directly block the KIR receptor with an antibody to inhibit its interaction with HLA ligand. However, in the MM clinical trial of the antiKIR antibody IPH2101, this approach was ineffective due to the 
monocytic trogocytosis of KIR molecules, eventually leading to the lack of education and hyporesponsiveness of NK cells (242). In addition, KIR downregulation leading to enhanced NK cell killing can be achieved also by the stimulation with IL-12, IL-15, and IL-18, while the expression can be restored back after 3 days of culture with IL-2, suggesting an interesting possibility of KIR exploitation with cytokine stimulation (243).

Recently, the upregulation of other possible novel therapeutic target molecules TIGIT, TIM-3, ICOS, and GITR on NK cells was proved in both the $\mathrm{PB}$ and $\mathrm{BM}$ of $\mathrm{MM}$ patients, which probably reflects on the additional immune evasion mechanism $(165,244)$. TIGIT is a newly identified NK cell immune checkpoint binding to PVR (CD155) and nectin-2 (CD112), which are shared ligands with activating molecule DNAM-1 (245). Nectin-2 was found to be overexpressed on MM PCs, and both PVR and nectin-2 expression were associated with poor prognosis in cancer $(246,247)$. TIGIT inhibition was proved to restore T-cell response in MM (248). Moreover, TIGIT ligands are highly expressed on cells residing in the BM, which also proposes a role of TIGIT signaling in the MM niche-mediated suppression of NK cell function (246). This is supported by the study showing that BM MSCs upregulate PVR on the surface of MM cells by IL- 8 secretion (249). Also, a specific role of MDSCs in the TIGIT/CD155 axis was found. Co-culture of MDSCs with NK cells inhibited their cytotoxic abilities; however, this effect can be reversed either by the inhibition of ROS production (which led to upregulation of PVR in MDSCs) or by the blockade of TIGIT (250). Upregulation of TIM-3, a molecule associated with both inhibitory and activating functions, was also linked with cancer progression as well as CD8+ T cell exhaustion (251-254). In NK cells, it was proved that interactions of TIM-3 with its ligands HMGB1, CEACAM, phosphatidylserine, and galectin-9 inhibit the cytokine production and killing abilities (255). CEACAM ligand overexpression was described in MM, and the expression of HMGB1 was connected to therapy resistance and poor prognosis $(256,257)$. However, CEACAM downregulation was also correlated with cancer progression (258). These findings may only reflect a heterogeneous role of TIM-3 in the regulation of NK cells in cancer. Further investigation of inhibitory receptors is definitely necessary not only in the context of MM.

\section{NK Cell Activating Receptors in MM}

Both increased and decreased expressions of activating receptors were described in MM. These complex phenotypic changes are attributed to chronic ligand exposure and subsequent NK cell exhaustion $(165,259,260)$. Ligands of these receptors were confirmed to be upregulated by MM PCs (238).

Downregulation of NKG2D, as well as 2B4/CD244 and NKp30, can be detected on BM NK cells but not in the PB of MGUS/MM patients (261). However, reduced levels of NKG2D (together with DNAM-1 and CD16) can be observed in both PB and BM of RR and post-SCT MM patients (165). These results reflect the fact that NK cell functional alteration is initiated in the MM BM and later, as the disease progresses, functional impairment is reflected even in circulating NK cells. NKG2D activation is induced by MHC-I-related ligands, which are upregulated as a signal of stress or malignant transformation (262). MIC-A, MIC-B, ULBP-1, ULBP-2, and ULBP-3 are wellknown ligands for NKG2D. However, cancer cells are able to downregulate and shed these molecules from their surface. It was shown that high volumes of soluble NKG2D ligands, together with exosomes, are released from tumor cells to chronically exhaust T and NK cells (263-265). However, contradictory data were also published showing that another soluble NKG2D ligand, MULT-1, promotes NK cell function and tumor killing in mice. Nonetheless, the question is whether long-term exposure would not lead to effector cell exhaustion as well (266). One of the mechanisms behind the downregulation and shedding of NKG2D ligands is most likely TGF- $\beta$-induced expression of MMP2 (218). MIF was also proved to contribute to the transcriptional downregulation of NGD2D in NK cells (267). Moreover, the expression of NKG2D and NKG2D ligands is downregulated by IDO (indoleamine-2,3-dioxygenase) (268). Recently, CAR-NK cells transduced to express NKG2D-CAR showed a very good anti-myeloma efficacy in vivo, with minimal activity against healthy cells. Considering the greater efficacy and lesser toxicity compared to CAR-T cells, these are promising results reflecting the possible use of autologous-engineered CARNK cells in the treatment of MM (269).

SLAMF7 (CS1, CRACC, and CD319) is a surface signaling lymphocytic activation molecule (SLAM family) expressed on NK cells and PCs (both normal and malignant), while undetectable in other cells, which makes it a valid target for MM therapy $(270,271)$. Increased levels of surface SLAMF7 on NK cells were correlated with a worse prognosis in MM (165). Moreover, malignant PCs were proved to cleave SLAMF7 from their surface, leading to increased levels of soluble SLAMF7, which can be detected in MM patients, but not in MGUS. Thus, levels of SLAMF7 can be associated with disease progression. Data also confirmed that soluble SLAMF7 promotes MM cell growth via interaction with surface SLAMF7 on MM cells, with subsequent activation of ERK and SHP-2 signaling (272). Furthermore, it was predicted that soluble SLAMF7 could potentially interfere with the novel targeted therapy (273). Anti-SLAMF7 elotuzumab was FDA-approved in 2015, and since then, it has shown promising results in clinical studies. Elotuzumab in combination with lenalidomide and dexamethasone or bortezomib showed increased effectiveness and sustained benefit in progression free survival (274-276). In NK cells, elotuzumab binds to the CD16, which mediates ADCC against the anti-SLAMF7 antibody coupled with SLAMF7 on MM cells. Also, other mechanisms of action include NK cell costimulation through NKp30 and NKG2D, stimulation of IFN- $\gamma$ and granzyme B secretion, as well as macrophage-mediated antibody dependent cell phagocytosis (276, 277). Very intriguing are findings indicating that anti-SLAMF7 antibodies disrupt adhesion of MM PCs to MSCs in the BM. This indicates that elotuzumab might be one of the pioneering agents with a multiple-hit strategy, both against malignant PCs as well as MM niche components (267). 
As already mentioned, other activating receptors were proved to be downregulated in MM, including DNAM-1, 2B4 (CD244), and CD16 $(165,261)$. TGF- $\beta$ was confirmed as one of the factors causing the downregulation of $2 \mathrm{~B} 4$ and $2 \mathrm{~B} 4$ adaptor proteins (DAP10 and SAP) $(278,279)$. Early studies on 2B4 showed an activating function of this receptor leading to increased killing and IFN- $\gamma$ production; nonetheless, further research also proved an inhibitory role of this molecule $(280,281)$. Upregulation of 2B4 and downregulation of the associated adaptor protein SAP were related with inhibitory signaling, while downregulation of 2B4 and normal levels of SAP were associated with activating signaling (282). Among others, downregulation of 2B4 results in defective interactions with its ligand CD48. This also affects the co-stimulation of NCRs mediated through the 2B4-CD48 signaling (259). Lately, 2B4, which is also a member of SLAM family, was proposed as a target for immunotherapy, which could potentially have a double-hit impact affecting MM niche similar to SLAMF7. In particular, 2B4 expression was confirmed on MDSCs (283). Downregulation of CD16 logically results in impaired ADCC (259). However, counterintuitively, it was published that shedding of CD16 from the surface of NK cells leads to the positive stimulation of the immune response by engagement of other immune cells (284). Indeed, levels of soluble CD16 in the serum are significantly decreased in patients with MM compared to MGUS or healthy donors. This was also correlated with the disease staging (285).

The NCR family consists of 3 receptors: NKp30 (NCR3), NKp44 (NCR2), and NKp46 (NCR1). These molecules were originally categorized as activating receptors; nonetheless, it seems that different isoforms of NCRs may exist based on the environment, which then deliver either activating or inhibitory response. Blocking of individual NCRs with mAbs is rather ineffective, while effective inhibition caused by a combination of mAbs against multiple NCR receptors suggest a cooperative mechanism in the process of NK cell activation $(286,287)$. A positive role of NCRs in cancer control was proved by several studies. NKp46 was connected to metastatic prevention and the potentiation of NK cell antitumor activity by increased IFN- $\gamma$ production $(288,289)$. Nevertheless, the activity and function of NCRs can be downregulated in cancer, which, particularly in $\mathrm{NKp46}$, is associated with the progression of malignancy too (290, 291). In MM, NKp30 was proved to be downregulated on BM NK cells, but not in the PB (261). Also, increased expression of NKp30 (on CD56dim CD16+ subset) and NKp44 (CD56bright CD16- and CD56dim CD16+) and decreased expression of NKp44 (CD56bright CD16-) can be observed on PB NK cells in RR MM, but it is not possible to detect any similar changes in ND MM. Again, these data support the fact that functional NK cell properties are impaired preferentially in the site of disease manifestation, and that the impairment is minor (or the function is restored) in circulating NK cells during early states of MM. However, as the disease progresses, further dysfunctional evolution is reflected even in PB NK cells (165). NCRs can be activated by different viral and bacterial ligands, growth factors, ECM-derived and membrane-derived components, or stress related ligands (286). In cancer, several molecules were proved to play a role in NCR activation and cancer cell elimination, though data related to NCR ligands in cancer cells is scarce. B7-H6, BAG-6, and Galectin-3 were confirmed as NKp30 ligands. PCNA, NKp44L (a MLL5-variant protein), and PDGF-DD (platelet-derived growth factor isoform) are among the ligands of NKp44 that might play a role in cancer cell elimination (292-294). However, similarly to what was described in NKG2D ligand shedding, cleavage of B7-H6 ligands by the ADAM-10 and ADAM-17 MMP-related mechanism was showed to chronically exhaust NK cell actions mediated through the NKp30 receptor $(295,296)$. Galectin-3 can also be released in soluble form by cancer cells to inhibit the NKp30 function (297). Furthermore, tumor-derived TGF- $\beta$ is one of the factors involved in NKp30 downmodulation (298). In hypoxic conditions, NK cells upregulate HIF-1 $\alpha$, and, curiously, maintain the killing abilities mediated via CD16. Nonetheless, the function of activating receptors, including NKp30, NKp44, and NKp46, is impaired (299). NCR-related therapeutical options are not clearly elucidated, though NKp30 was proposed as a target for immunotherapy. However, only CAR$\mathrm{T}$ cells targeting this receptor has been explored, and data relevant to anti-NKp30 mAbs are still missing. Further research is needed regarding the NCR impairment, ligand identification and expression, as well as possible therapeutic options (300).

\section{Impact of Anti-Myeloma Therapy on NK Cells}

As already mentioned, NK cells are important cells mediating the anti-tumor effect of novel mAbs used in the treatment of MM, such as daratumumab, isatuximab, or elotuzumab, and induction of ADCC represents one of several important mechanisms of action induced by these antibodies. Moreover, additional effects of daratumumab mediated via NK cells were described, including monocyte activation, phagocytosis, and increased $\mathrm{T}$ cell costimulatory abilities. Hence, any disruption of NK cell immune function might be of great concern and the overall impact of anti-myeloma therapy, including the above-mentioned mAbs, immunomodulatory drugs (IMiDs), or proteasome inhibitors, on NK cells needs to be studied thoroughly (301).

Since CD38 is expressed on the surface of NK cells as well, the question of whether anti-CD38 agents negatively affect or even possibly kill NK cells was raised. Indeed, it was described that daratumumab depletes CD38+ MDSCs, B cells, and Tregs (302). Data published 2 years later confirmed that CD38+ NK cells are also subjected to ADCC induced by daratumumab bound on their surface, which suggested an alarming issue of anti-CD38 therapy (303). A significant reduction of NK cell numbers can be detected in $\mathrm{PB}$ and $\mathrm{BM}$ of $\mathrm{MM}$ patients after initiation of the daratumumab-containing therapy, with the persistence of low NK cell counts during the whole course of the treatment. Nonetheless, no adverse effects on the overall efficacy of the therapy or function of NK cells were discovered. Furthermore, additional immunomodulatory mechanisms of daratumumab participating in the overall therapy efficacy were shown, including increased frequency of $\mathrm{CD} 8+\mathrm{T}$ cells with 
preferential generation of effector memory subset $(304,305)$. Isatuximab was described to mediate even stronger efficacy in the killing of target cells compared to daratumumab, and also the drug was confirmed to induce apoptosis of Tregs with higher CD38 expression than other $\mathrm{T}$ cells (28). Similar to daratumumab, reduction of NK cells can be observed after isatuximab application as well, together with the depletion of CD38high B-lymphoid progenitors. Isatuximab-treated NK cells exhibit deregulation of 70 genes, mostly connected to chemotaxis, cytolysis, and immune defense response (28, 95, 306). Anti-SLAMF7 mAb elotuzumab also strongly stimulates NK cell activation, induction of ADCC, and degranulation via engagement of CD16. Calcium signaling costimulation triggered by engagement of NKp46 and NKG2D in CD16-independent manner is also activated by this antibody. Regimens containing elotuzumab plus lenalidomide or bortezomib showed promising results, while no adverse effects of elotuzumab on the overall function or frequency of NK cells were observed (307).

Furthermore, proteasome inhibitors such as bortezomib or carfilzomib were described to potentiate NK cell cytotoxicity against MM cells, while no considerable adverse effects on NK cells were reported. Sensitization by downregulation of HLA-I molecules on the surface of malignant PCs is one of the involved mechanisms. Other mechanisms were revealed in studies involving other types of cancer, including bortezomib-induced upregulation of NK cell activating receptor ligands (MIC-A/B, ULBP-1) or ligands related to the death receptor signaling (Fas, DR-5) (308-310).

Immunomodulatory drugs (IMiDs), such as thalidomide, lenalidomide, and pomalidomide, significantly improved therapy outcome in the past two decades and represent indispensable agents that are used to treat MM (311). These agents exhibit pleiotropic anti-MM potential, including antiangiogenic, anti-inflammatory, immunomodulatory, and antiproliferative effects (312). In theory, earlier it was proposed that IMiDs could enhance impaired function of immune cells. As a matter of fact, studies confirmed that increased numbers of NK cells can be detected in patients receiving thalidomide therapy, and the positive effect of IMiDs on costimulation of T cells, NK cell proliferation, and their cytotoxic abilities was confirmed as well. Upregulation of IL-2 signaling, along with upregulation of PVR and MIC-A ligands, was discovered to participate in the IMiD-mediated stimulation of NK cells (312-314). Nonetheless, no positive effect of lenalidomide on NK cell activation, degranulation or secretion of IFN- $\gamma$ or MIP1- $\beta$ was observed in the study that was monitoring NK cell activity and functionality in $10 \mathrm{MM}$ patients treated with lenalidomidecontaining regimen and then maintained with lenalidomide. Progressive post-maintenance NK cell lineage normalization was observed, albeit this was possibly caused by the chemotherapy discontinuation (315). On the other hand, a positive effect of pomalidomide on innate lymphoid cells (ILCs), which are recently discussed lymphoid cells with antitumor potential, was described. Results indicate that pomalidomide leads to enhancement of ILC function through the stimulation of IFN- $\gamma$ production as well as downregulation of
Ikzf1 and Ikzf3, which are transcription factors essential for MM cell proliferation. Similar degradation by ubiquitination of Ikzf1 and Ikzf3 was confirmed by lenalidomide $(316,317)$.

\section{DISCUSSION}

Defects of NK cell cytokine production, chemotaxis, maturation, effector molecule expression, and related target recognition and killing are described in the context of MM BM or TME in general, although clearly there are large gaps in current knowledge. Unfortunately, some data are even contradictory probably due to the complexity and heterogeneity of the malignant niche and occurring interactions. An overall disruption of NK cell function was correlated with MM and cancer progression; thus, potentiating and restoring the proper NK cell abilities, maturation, and BM localization, as well as normalizing the BM niche, are for sure among the goals for future improvement of patients' survival and quality of life.

Data covering interactions between NK cells and individual cellular or non-cellular components of the MM niche, which would describe particular mechanisms of NK cell functional impairment, are extensively incomplete. Furthermore, additional information about disrupted NK cell chemokine signaling during MM progression are needed. Data describing the distribution of NK progenitors in the malignant marrow in general are missing completely. Similarly, there is only limited information about mechanisms behind the NK cell maturation distortion during disease progression in the BM. Restoring the generation of fully functional NK cells with normal chemotactic abilities may be critical for the future improvement of therapeutic options. Furthermore, data related to NK cell immune monitoring and expression profiles of surface effector molecules in the EMD are missing. These would provide critical information about the functional capacities of these cells, as well as about levels of potential targets.

Altogether, NK cells and their surface effector molecules represent a tempting therapeutic target in $\mathrm{MM}$ and other malignancies, although recent data suggest that combination with conventional protocols is needed in the present. Thus, further research that would uncover all the possible interactions between these receptors, their cognate ligands, as well as interfering factors and cells in the malignant niche is necessary. Moreover, all the data highlight the necessity of further research in the field of IMiDs as well as novel mAbs and proteasome inhibitors used for the treatment of MM. Their mechanisms of action or impact on NK cells or ILCs is still not fully understood. Promising results were published, but unfortunately, most of the available data were generated by in vitro or in vivo assays, and studies involving MM patients are scarce.

\section{AUTHOR CONTRIBUTIONS}

All authors made a substantial contribution to the manuscript preparation. OV prepared graphical figures, and conceived and 
wrote the review. JB, BM, TJ, and $\mathrm{RH}$ commented and edited first versions of the manuscript and participated on the final version. All authors contributed to the article and approved the submitted version.

\section{FUNDING}

This work has been supported by the project Cell Coolab Ostrava-Research and Development Center for Cell Therapy in Hematology and Oncology (No. CZ.02.1.01/0.0/0.0/17_049/

\section{REFERENCES}

1. Rajkumar SV. Multiple Myeloma: 2020 Update on Diagnosis, RiskStratification And Management. Am J Hematol (2020) 95(5):548-67. doi:10.1002/ajh.25791.

2. Kyle RA, Rajkumar SV. Treatment of Multiple Myeloma: A Comprehensive Review. Clin Lymph Myeloma (2009) 9(4):278-88. doi: 10.3816/ CLM.2009.n.056

3. Blade J, de Larrea CF, Rosinol L. Extramedullary Involvement in Multiple Myeloma. Haematologica (2012) 97(11):1618-9. doi: 10.3324/haematol. 2012.078519

4. Bladé J, Fernández de Larrea C, Rosiñol L, Cibeira MT, Jiménez R, Powles R. Soft-Tissue Plasmacytomas in Multiple Myeloma: Incidence, Mechanisms of Extramedullary Spread, and Treatment Approach. J Clin Oncol Off J Am Soc Clin Oncol (2011) 29(28):3805-12. doi: 10.1200/ JCO.2011.34.9290

5. Jelinek T, Sevcikova T, Zihala D, Popkova T, Kapustova V, Broskevicova L, et al. Limited Efficacy of Daratumumab in Multiple Myeloma With Extramedullary Disease. Leukemia (2021), 1-4. doi: 10.1038/s41375-02101343-w Published online July 10.

6. Sevcikova S, Minarik J, Stork M, Jelinek T, Pour L, Hajek R. Extramedullary Disease in Multiple Myeloma - Controversies and Future Directions. Blood Rev (2019) 36:32-9. doi: 10.1016/j.blre.2019.04.002

7. Besse L, Sedlarikova L, Greslikova H, Kupska R, Almasi M, Penka M, et al. Cytogenetics in Multiple Myeloma Patients Progressing Into Extramedullary Disease. Eur J Haematol (2016) 97(1):93-100. doi: 10.1111/ejh.12688

8. Shimasaki N, Jain A, Campana D. NK Cells for Cancer Immunotherapy. Nat Rev Drug Discov (2020) 19(3):200-18. doi: 10.1038/s41573-019-0052-1

9. Lamb MG, Rangarajan HG, Tullius BP, Lee DA. Natural Killer Cell Therapy for Hematologic Malignancies: Successes, Challenges, and the Future. Stem Cell Res Ther (2021) 12:1-19. doi: 10.1186/s13287-021-02277-x

10. Ben-Shmuel A, Biber G, Barda-Saad M. Unleashing Natural Killer Cells in the Tumor Microenvironment-The Next Generation of Immunotherapy? Front Immunol (2020) 11:275. doi: 10.3389/fimmu.2020.00275

11. Heinze A, Grebe B, Bremm M, Huenecke S, Munir TA, Graafen L, et al. The Synergistic Use of IL-15 and IL-21 for the Generation of NK Cells From CD3/CD19-Depleted Grafts Improves Their Ex Vivo Expansion and Cytotoxic Potential Against Neuroblastoma: Perspective for Optimized Immunotherapy Post Haploidentical Stem Cell Transplantation. Front Immunol (2019) 10. doi: 10.3389/fimmu.2019.02816

12. Khan AM, Devarakonda S, Bumma N, Chaudhry M, Benson DM. Potential of NK Cells in Multiple Myeloma Therapy. Expert Rev Hematol (2019) 12 (6):425-35. doi: 10.1080/17474086.2019.1617128

13. Paul S, Lal G. The Molecular Mechanism of Natural Killer Cells Function and Its Importance in Cancer Immunotherapy. Front Immunol (2017) 8. doi: 10.3389/fimmu.2017.01124

14. Ames E, Murphy WJ. Advantages and Clinical Applications of Natural Killer Cells in Cancer Immunotherapy. Cancer Immunol Immunother CII (2014) 63:21-8. doi: 10.1007/s00262-013-1469-8

15. Basar R, Daher M, Rezvani K. Next-Generation Cell Therapies: The Emerging Role of CAR-NK Cells. Blood Adv (2020) 4(22):5868-76. doi: 10.1182/bloodadvances.2020002547
0008440), European Regional Development Fund-Project ENOCH (No. CZ.02.1.01/0.0/0.0/16_019/0000868, Student's grant system SGS15/PrF/2021 University of Ostrava and Institutional support University Hospital Ostrava MH CZ DRO (FNOs/2021).

\section{ACKNOWLEDGMENTS}

The authors would like to thank Shira Timilsina Godfrey, M.D., for the language correction.

16. Jaiswal SR, Zaman S, Nedunchezhian M, Chakrabarti A, Bhakuni P, Ahmed $\mathrm{M}$, et al. CD56-Enriched Donor Cell Infusion After Post-Transplantation Cyclophosphamide for Haploidentical Transplantation of Advanced Myeloid Malignancies Is Associated With Prompt Reconstitution of Mature Natural Killer Cells and Regulatory T Cells With Reduced Incidence of Acute Graft Versus Host Disease: A Pilot Study. Cytother (2017) 19(4):531-42. doi: 10.1016/j.jcyt.2016.12.006

17. Alici E, Sutlu T, Björkstrand B, Gilljam M, Stellan B, Nahi H, et al Autologous Antitumor Activity by NK Cells Expanded From Myeloma Patients Using GMP-Compliant Components. Blood (2008) 111(6):3155-62. doi: 10.1182/blood-2007-09-110312

18. Alfarra H, Weir J, Grieve S, Reiman T. Targeting NK Cell Inhibitory Receptors for Precision Multiple Myeloma Immunotherapy. Front Immunol (2020) 11:575609. doi: 10.3389/fimmu.2020.575609

19. Chen Y, Lu D, Churov A, Fu R. Research Progress on NK Cell Receptors and Their Signaling Pathways. Mediators Inflamm (2020) 2020:e6437057. doi: $10.1155 / 2020 / 6437057$

20. Tognarelli S, Wirsching S, von Metzler I, Rais B, Jacobs B, Serve H, et al. Enhancing the Activation and Releasing the Brakes: A Double Hit Strategy to Improve NK Cell Cytotoxicity Against Multiple Myeloma. Front Immunol (2018) 9:2743. doi: 10.3389/fimmu.2018.02743

21. Szczepanski MJ, Szajnik M, Welsh A, Foon KA, Whiteside TL, Boyiadzis M Interleukin-15 Enhances Natural Killer Cell Cytotoxicity in Patients With Acute Myeloid Leukemia by Upregulating the Activating NK Cell Receptors. Cancer Immunol Immunother CII (2010) 59(1):73-9. doi: 10.1007/s00262009-0724-5

22. Alonso Fernández R. Restoring NK Cell Activities in Multiple Myeloma With IL-15 Receptor Agonist NKTR-255. In: ASH (2020). Available at: https://ash.confex.com/ash/2020/webprogram/Paper140395.html (Accessed April 15, 2021).

23. Van Elssen C, van Gorkom G, Voorter C, von dem Borne P, Meijer E Wieten L, et al. Haploidentical Transplantation in Patients With Multiple Myeloma Making Use of Natural Killer Cell Alloreactive Donors. Ann Hematol (2021) 100(1):181-7. doi: 10.1007/s00277-020-04303-z

24. van de Donk NWCJ, Moreau P, Plesner T, Palumbo A, Gay F, Laubach JP, et al. Clinical Efficacy and Management of Monoclonal Antibodies Targeting CD38 and SLAMF7 in Multiple Myeloma. Blood (2016) 127(6):681-95. doi: 10.1182/blood-2015-10-646810

25. Zahavi D, Weiner L. Monoclonal Antibodies in Cancer Therapy. Antibodies (2020) 9:1-20. doi: 10.3390/antib9030034

26. Jelinek T, Hajek R. Monoclonal Antibodies - A New Era in the Treatment of Multiple Myeloma. Blood Rev (2016) 30(2):101-10. doi: 10.1016/j.blre. 2015.08.004

27. Sherbenou DW, Mark TM, Forsberg P. Monoclonal Antibodies in Multiple Myeloma: A New Wave of the Future. Clin Lymphoma Myeloma Leuk (2017) 17(9):545-54. doi: 10.1016/j.clml.2017.06.030

28. Moreno L, Perez C, Zabaleta A, Manrique I, Alignani D, Ajona D, et al. The Mechanism of Action of the Anti-CD38 Monoclonal Antibody Isatuximab in Multiple Myeloma. Clin Cancer Res Off J Am Assoc Cancer Res (2019) 25 (10):3176-87. doi: 10.1158/1078-0432.CCR-18-1597

29. Raab MS, Engelhardt M, Blank A, Goldschmidt H, Agis H, Blau IW, et al MOR202, a Novel Anti-CD38 Monoclonal Antibody, in Patients With Relapsed or Refractory Multiple Myeloma: A First-in-Human, 
Multicentre, Phase 1-2a Trial. Lancet Haematol (2020) 7(5):e381-94. doi: 10.1016/S2352-3026(19)30249-2

30. Pascal V, Schleinitz N, Brunet C, Ravet S, Bonnet E, Lafarge X, et al. Comparative Analysis of NK Cell Subset Distribution in Normal and Lymphoproliferative Disease of Granular Lymphocyte Conditions. Eur J Immunol (2004) 34(10):2930-40. doi: 10.1002/eji.200425146

31. Dogra P, Rancan C, Ma W, Toth M, Senda T, Carpenter DJ, et al. Tissue Determinants of Human NK Cell Development, Function, and Residence. Cell (2020) 180(4):749-763.e13. doi: 10.1016/j.cell.2020.01.022

32. Carrega P, Ferlazzo G. Natural Killer Cell Distribution and Trafficking in Human Tissues. Front Immunol (2012) 3. doi: 10.3389/fimmu.2012.00347

33. Yu J, Freud AG, Caligiuri MA. Location and Cellular Stages of NK Cell Development. Trends Immunol (2013) 34(12):573-82. doi: 10.1016/ j.it.2013.07.005

34. Scoville SD, Freud AG, Caligiuri MA. Modeling Human Natural Killer Cell Development in the Era of Innate Lymphoid Cells. Front Immunol (2017) 8. doi: 10.3389/fimmu.2017.00360

35. Abel AM, Yang C, Thakar MS, Malarkannan S. Natural Killer Cells: Development, Maturation, and Clinical Utilization. Front Immunol (2018) 9. doi: 10.3389/fimmu.2018.01869

36. Kalland T. Generation of Natural Killer Cells From Bone Marrow Precursors. vitro Immunol (1986) 57(4):493-8.

37. Dmytrus J, Matthes-Martin S, Pichler H, Worel N, Geyeregger R, Frank N, et al. Multi-Color Immune-Phenotyping of CD34 Subsets Reveals Unexpected Differences Between Various Stem Cell Sources. Bone Marrow Transplant (2016) 51(8):1093-100. doi: 10.1038/bmt.2016.88

38. Görgens A, Radtke S, Möllmann M, Cross M, Dürig J, Horn PA, et al. Revision of the Human Hematopoietic Tree: Granulocyte Subtypes Derive From Distinct Hematopoietic Lineages. Cell Rep (2013) 3(5):1539-52. doi: 10.1016/j.celrep.2013.04.025

39. Carotta S, Pang SHM, Nutt SL, Belz GT. Identification of the Earliest NKCell Precursor in the Mouse BM. Blood (2011) 117(20):5449-52. doi: 10.1182/blood-2010-11-318956

40. Renoux VM, Zriwil A, Peitzsch C, Michaëlsson J, Friberg D, Soneji S, et al. Identification of a Human Natural Killer Cell Lineage-Restricted Progenitor in Fetal and Adult Tissues. Immun (2015) 43(2):394-407. doi: 10.1016/ j.immuni.2015.07.011

41. Boos MD, Ramirez K, Kee BL. Extrinsic and Intrinsic Regulation of Early Natural Killer Cell Development. Immunol Res (2008) 40(3):193-207. doi: 10.1007/s12026-007-8006-9

42. Fathman JW, Bhattacharya D, Inlay MA, Seita J, Karsunky H, Weissman IL. Identification of the Earliest Natural Killer Cell-Committed Progenitor in Murine Bone Marrow. Blood (2011) 118(20):5439-47. doi: 10.1182/blood2011-04-348912

43. Ziegler S, Weiss E, Schmitt AL, Schlegel J, Burgert A, Terpitz U, et al. CD56 Is a Pathogen Recognition Receptor on Human Natural Killer Cells. Sci Rep (2017) 7(1):6138. doi: 10.1038/s41598-017-06238-4

44. Mace EM, Hsu AP, Monaco-Shawver L, Makedonas G, Rosen JB, Dropulic L, et al. Mutations in GATA2 Cause Human NK Cell Deficiency With Specific Loss of the CD56bright Subset. Blood (2013) 121(14):2669-77. doi: 10.1182/blood-2012-09-453969

45. Lysakova-Devine T, O’Farrelly C. Tissue-Specific NK Cell Populations and Their Origin. J Leukoc Biol (2014) 96(6):981-90. doi: 10.1189/jlb.1RU0514$241 \mathrm{R}$

46. Aggarwal N, Swerdlow SH, TenEyck SP, Boyiadzis M, Felgar RE. Natural Killer Cell (NK) Subsets and NK-Like T-Cell Populations in Acute Myeloid Leukemias and Myelodysplastic Syndromes. Cytometry B Clin Cytom (2016) 90(4):349-57. doi: 10.1002/cyto.b.21349

47. Poli A, Michel T, Thérésine M, Andrès E, Hentges F, Zimmer J. CD56bright Natural Killer (NK) Cells: An Important NK Cell Subset. Immunol (2009) 126(4):458-65. doi: 10.1111/j.1365-2567.2008.03027.x

48. Campbell KS, Hasegawa J. NK Cell Biology: An Update and Future Directions. J Allergy Clin Immunol (2013) 132(3):536-44. doi: 10.1016/ j.jaci.2013.07.006

49. Bassani B, Baci D, Gallazzi M, Poggi A, Bruno A, Mortara L. Natural Killer Cells as Key Players of Tumor Progression and Angiogenesis: Old and Novel Tools to Divert Their Pro-Tumor Activities Into Potent Anti-Tumor Effects. Cancers (2019) 11(4):461. doi: 10.3390/cancers11040461
50. Cooper MA, Fehniger TA, Caligiuri MA. The Biology of Human Natural Killer-Cell Subsets. Trends Immunol (2001) 22(11):633-40. doi: 10.1016/ s1471-4906(01)02060-9

51. Lopez-Vergès S, Milush JM, Pandey S, York VA, Arakawa-Hoyt J, Pircher H, et al. CD57 Defines a Functionally Distinct Population of Mature NK Cells in the Human CD56dimCD16+ NK-Cell Subset. Blood (2010) 116 (19):3865-74. doi: 10.1182/blood-2010-04-282301

52. Mavilio D, Lombardo G, Benjamin J, Kim D, Follman D, Marcenaro E, et al. Characterization of CD56-/CD16+ Natural Killer (NK) Cells: A Highly Dysfunctional NK Subset Expanded in HIV-Infected Viremic Individuals. Proc Natl Acad Sci USA (2005) 102(8):2886-91. doi: 10.1073/ pnas.0409872102

53. Milush JM, López-Vergès S, York VA, Deeks SG, Martin JN, Hecht FM, et al. CD56negCD16+NK Cells are Activated Mature NK Cells With Impaired Effector Function During HIV-1 Infection. Retrovirology (2013) 10(1):158. doi: $10.1186 / 1742-4690-10-158$

54. Hayakawa Y, Smyth MJ. CD27 Dissects Mature NK Cells Into Two Subsets With Distinct Responsiveness and Migratory Capacity. J Immunol (2006) 176(3):1517-24. doi: 10.4049/jimmunol.176.3.1517

55. Fu B, Wang F, Sun R, Ling B, Tian Z, Wei H. CD11b and CD27 Reflect Distinct Population and Functional Specialization in Human Natural Killer Cells. Immunol (2011) 133(3):350-9. doi: 10.1111/j.1365-2567.2011. 03446.x

56. Horowitz A, Strauss-Albee DM, Leipold M, Kubo J, Nemat-Gorgani N, Dogan OC, et al. Genetic and Environmental Determinants of Human NK Cell Diversity Revealed by Mass Cytometry. Sci Transl Med (2013) 5 (208):208ra145. doi: 10.1126/scitranslmed.3006702

57. Nicholson SE, Keating N, Belz GT. Natural Killer Cells and Anti-Tumor Immunity. Mol Immunol (2019) 110:40-7. doi: 10.1016/j.molimm. 2017.12.002

58. Sungur CM, Murphy WJ. Positive and Negative Regulation by NK Cells in Cancer. Crit Rev Oncog (2014) 19(0):57-66. doi: 10.1615/CritRevOncog. 2014010805

59. Peng H, Tian Z. Natural Killer Cell Memory: Progress and Implications. Front Immunol (2017) 8:1143. doi: 10.3389/fimmu.2017.01143

60. Yoon SR, Kim TD, Choi I. Understanding of Molecular Mechanisms in Natural Killer Cell Therapy. Exp Mol Med (2015) 47(2):e141-1. doi: 10.1038/ emm.2014.114

61. Konjević G, Vuletić A, Martinović KM, Džodić R. The Role of Activating and Inhibitory NK Cell Receptors in Antitumor Immune Response. IntechOpen (2017) 69:49-65. doi: 10.5772/intechopen.69729

62. Maria AD, Bozzano F, Cantoni C, Moretta L. Revisiting Human Natural Killer Cell Subset Function Revealed Cytolytic CD56dimCD16+ NK Cells as Rapid Producers of Abundant IFN- $\gamma$ on Activation. Proc Natl Acad Sci (2011) 108(2):728-32. doi: 10.1073/pnas.1012356108

63. Fauriat C, Long EO, Ljunggren HG, Bryceson YT. Regulation of Human NK-Cell Cytokine and Chemokine Production by Target Cell Recognition. Blood (2010) 115(11):2167-76. doi: 10.1182/blood-2009-08-238469

64. Street SE, Cretney E, Smyth MJ. Perforin and Interferon-Gamma Activities Independently Control Tumor Initiation, Growth, and Metastasis. Blood (2001) 97(1):192-7. doi: 10.1182/blood.v97.1.192

65. Smyth MJ, Cretney E, Kelly JM, Westwood JA, Street SEA, Yagita H, et al. Activation of NK Cell Cytotoxicity. Mol Immunol (2005) 42(4):501-10. doi: 10.1016/j.molimm.2004.07.034

66. Topham NJ, Hewitt EW. Natural Killer Cell Cytotoxicity: How do They Pull the Trigger? Immunol (2009) 128(1):7-15. doi: 10.1111/j.1365-2567. 2009.03123.x

67. Guicciardi ME, Gores GJ. Life and Death by Death Receptors. FASEB J (2009) 23(6):1625-37. doi: 10.1096/fj.08-111005

68. Kumar R, Herbert PE, Warrens AN. An Introduction to Death Receptors in Apoptosis. Int J Surg (2005) 3(4):268-77. doi: 10.1016/j.ijsu.2005.05.002

69. Lo Nigro C, Macagno M, Sangiolo D, Bertolaccini L, Aglietta M, Merlano MC. NK-Mediated Antibody-Dependent Cell-Mediated Cytotoxicity in Solid Tumors: Biological Evidence and Clinical Perspectives. Ann Transl Med (2019). doi: 10.21037/atm.2019.01.42

70. Sordo-Bahamonde C, Lorenzo-Herrero S, Payer ÁR, Gonzalez S, López-Soto A. Mechanisms of Apoptosis Resistance to NK Cell-Mediated Cytotoxicity in Cancer. Int J Mol Sci (2020) 21(10):419-26. doi: 10.3390/ijms21103726 
71. Ljunggren HG, Kärre K. In Search of the "Missing Self": MHC Molecules and NK Cell Recognition. Immunol Today (1990) 11(7):237-44. doi: 10.1016/0167-5699(90)90097-s

72. Anfossi N, André P, Guia S, Falk CS, Roetynck S, Stewart CA, et al. Human NK Cell Education by Inhibitory Receptors for MHC Class I. Immun (2006) 25(2):331-42. doi: 10.1016/j.immuni.2006.06.013

73. He Y, Tian Z. NK Cell Education via Nonclassical MHC and NonMHC Ligands. Cell Mol Immunol (2017) 14(4):321-30. doi: 10.1038/ cmi.2016.26

74. Leung KK, Wilson GM, Kirkemo LL, Riley NM, Coon JJ, Wells JA. Broad and Thematic Remodeling of the Surfaceome and Glycoproteome on Isogenic Cells Transformed With Driving Proliferative Oncogenes. Proc Natl Acad Sci (2020) 117(14):7764-75. doi: 10.1073/pnas.1917947117

75. Algarra I, Cabrera T, Garrido F. The HLA Crossroad in Tumor Immunology. Hum Immunol (2000) 61(1):65-73. doi: 10.1016/s0198-8859 (99)00156-1

76. Khanna R. Tumour Surveillance: Missing Peptides and MHC Molecules. Immunol Cell Biol (1998) 76(1):20-6. doi: 10.1046/j.1440-1711.1998.00717.x

77. Cao Y, Wang X, Jin T, Tian Y, Dai C, Widarma C, et al. Immune Checkpoint Molecules in Natural Killer Cells as Potential Targets for Cancer Immunotherapy. Signal Transduct Target Ther (2020) 5(1):1-19. doi: 10.1038/s41392-020-00348-8

78. Sivori S, Vacca P, Del Zotto G, Munari E, Mingari MC, Moretta L. Human NK Cells: Surface Receptors, Inhibitory Checkpoints, and Translational Applications. Cell Mol Immunol (2019) 16(5):430-41. doi: 10.1038/ s41423-019-0206-4

79. Zheng Y, Ma X, Su D, Zhang Y, Yu L, Jiang F, et al. The Roles of Siglec7 and Siglec9 on Natural Killer Cells in Virus Infection and Tumour Progression. J Immunol Res (2020) 2020:1-9. doi: 10.1155/2020/6243819

80. Sun H, Huang Q, Huang M, Wen H, Lin R, Zheng M, et al. Human CD96 Correlates to Natural Killer Cell Exhaustion and Predicts the Prognosis of Human Hepatocellular Carcinoma. Hepatol Baltim Md (2019) 70(1):168-83. doi: 10.1002/hep.30347

81. Long EO, Rajagopalan S. Stress Signals Activate Natural Killer Cells. J Exp Med (2002) 196(11):1399-402. doi: 10.1084/jem.20021747

82. Chan CJ, Smyth MJ, Martinet L. Molecular Mechanisms of Natural Killer Cell Activation in Response to Cellular Stress. Cell Death Differ (2014) 21 (1):5-14. doi: $10.1038 / \mathrm{cdd} .2013 .26$

83. Luetke-Eversloh M, Hammer Q, Durek P, Nordström K, Gasparoni G, Pink $\mathrm{M}$, et al. Human Cytomegalovirus Drives Epigenetic Imprinting of the IFNG Locus in NKG2Chi Natural Killer Cells. PloS Pathog (2014) 10(10): e1004441. doi: 10.1371/journal.ppat.1004441

84. Liu LL, Landskron J, Ask EH, Enqvist M, Sohlberg E, Traherne JA, et al. Critical Role of CD2 Co-Stimulation in Adaptive Natural Killer Cell Responses Revealed in NKG2C-Deficient Humans. Cell Rep (2016) 15 (5):1088-99. doi: 10.1016/j.celrep.2016.04.005

85. Wu N, Veillette A. SLAM Family Receptors in Normal Immunity and Immune Pathologies. Curr Opin Immunol (2016) 38:45-51. doi: 10.1016/ j.coi.2015.11.003

86. Barrow AD, Colonna M. Exploiting NK Cell Surveillance Pathways for Cancer Therapy. Cancers (2019) 11(1):55. doi: 10.3390/cancers11010055

87. Raulet DH, Guerra N. Oncogenic Stress Sensed by the Immune System: Role of NK Cell Receptors. Nat Rev Immunol (2009) 9(8):568-80. doi: 10.1038/ nri2604

88. Della Chiesa M, Sivori S, Carlomagno S, Moretta L, Moretta A. Activating KIRs and NKG2C in Viral Infections: Toward NK Cell Memory? Front Immunol (2015) 6. doi: 10.3389/fimmu.2015.00573

89. Alari-Pahissa E, Grandclément C, Jeevan-Raj B, Leclercq G, Veillette A, Held W. Activation by SLAM Family Receptors Contributes to NK Cell Mediated "Missing-Self" Recognition. PloS One (2016) 11(4):e0153236. doi: 10.1371/ journal.pone. 0153236

90. Veillette A. NK Cell Regulation by SLAM Family Receptors and SAP-Related Adapters. Immunol Rev (2006) 214:22-34. doi: 10.1111/j.1600065X.2006.00453.x

91. Ramírez-Ramírez D, Padilla-Castañeda S, Galán-Enríquez CS, Vadillo E, Prieto-Chávez JL, Jiménez-Hernández E, et al. CRTAM+ NK Cells Endowed With Suppressor Properties Arise in Leukemic Bone Marrow. J Leukoc Biol (2019) 105(5):999-1013. doi: 10.1002/JLB.MA0618-231R
92. Ogasawara K, Yoshinaga SK, Lanier LL. Inducible Costimulator Costimulates Cytotoxic Activity and IFN- $\gamma$ Production in Activated Murine NK Cells. J Immunol (2002) 169(7):3676-85. doi: 10.4049/ jimmunol.169.7.3676

93. Schlaphoff V, Lunemann S, Suneetha PV, Jaroszewicz J, Grabowski J, Dietz J, et al. Dual Function of the NK Cell Receptor 2b4 (CD244) in the Regulation of HCV-Specific CD8+ T Cells. PloS Pathog (2011) 7(5):e1002045. doi: 10.1371/journal.ppat.1002045

94. Ho EL, Carayannopoulos LN, Poursine-Laurent J, Kinder J, Plougastel B, Smith HRC, et al. Costimulation of Multiple NK Cell Activation Receptors by NKG2D. J Immunol (2002) 169(7):3667-75. doi: 10.4049/jimmunol. 169.7.3667

95. Zambello R, Barilà G, Manni S, Piazza F, Semenzato G. NK Cells and CD38: Implication for (Immuno)Therapy in Plasma Cell Dyscrasias. Cells (2020) 9 (3):768. doi: 10.3390/cells9030768

96. Mallone R, Funaro A, Zubiaur M, Baj G, Ausiello CM, Tacchetti C, et al. Signaling Through CD38 Induces NK Cell Activation. Int Immunol (2001) 13(4):397-409. doi: 10.1093/intimm/13.4.397

97. Takeda K, Oshima H, Hayakawa Y, Akiba H, Atsuta M, Kobata T, et al. CD27-Mediated Activation of Murine NK Cells. J Immunol (2000) 164 (4):1741-5. doi: 10.4049/jimmunol.164.4.1741

98. Galán-Díez M, Cuesta-Domínguez Á, Kousteni S. The Bone Marrow Microenvironment in Health and Myeloid Malignancy. Cold Spring Harb Perspect Med (2018) 8(7):a031328. doi: 10.1101/cshperspect.a031328

99. Manier S, Sacco A, Leleu X, Ghobrial IM, Roccaro AM. Bone Marrow Microenvironment in Multiple Myeloma Progression. J BioMed Biotechnol (2012) 2012:157496. doi: 10.1155/2012/157496

100. Cheng H, Sun G, Cheng T. Hematopoiesis and Microenvironment in Hematological Malignancies. Cell Regen (2018) 7(1):22-6. doi: 10.1016/ j.cr.2018.08.002

101. Ghobrial IM, Detappe A, Anderson KC, Steensma DP. The Bone-Marrow Niche in MDS and MGUS: Implications for AML and MM. Nat Rev Clin Oncol (2018) 15(4):219-33. doi: 10.1038/nrclinonc.2017.197

102. Zavidij O, Haradhvala NJ, Mouhieddine TH, Sklavenitis-Pistofidis R, Cai S, Reidy M, et al. Single-Cell RNA Sequencing Reveals Compromised Immune Microenvironment in Precursor Stages of Multiple Myeloma. Nat Cancer (2020) 1(5):493-506. doi: 10.1038/s43018-020-0053-3

103. Roccaro AM, Sacco A, Maiso P, Azab AK, Tai YT, Reagan M, et al. BM Mesenchymal Stromal Cell-Derived Exosomes Facilitate Multiple Myeloma Progression. J Clin Invest (2013) 123(4):1542-55. doi: 10.1172/JCI66517

104. Psaila B, Lyden D. The Metastatic Niche: Adapting the Foreign Soil. Nat Rev Cancer (2009) 9(4):285-93. doi: 10.1038/nrc2621

105. García-Ortiz A, Rodríguez-García Y, Encinas J, Maroto-Martín E, Castellano E, Teixidó J, et al. The Role of Tumor Microenvironment in Multiple Myeloma Development and Progression. Cancers (2021) 13(2):217. doi: 10.3390/cancers 13020217

106. Robak P, Węgłowska E, Dróżdż I, Mikulski D, Jarych D, Ferlińska M, et al. Cytokine and Chemokine Profile in Patients With Multiple Myeloma Treated With Bortezomib. Mediators Inflamm (2020) 2020:1835836. doi: $10.1155 / 2020 / 1835836$

107. Cao Y, Luetkens T, Kobold S, Hildebrandt Y, Gordic M, Lajmi N, et al. The Cytokine/Chemokine Pattern in the Bone Marrow Environment of Multiple Myeloma Patients. Exp Hematol (2010) 38(10):860-7. doi: 10.1016/ j.exphem.2010.06.012

108. Botta C, Gullà A, Correale P, Tagliaferri P, Tassone P. Myeloid-Derived Suppressor Cells in Multiple Myeloma: Pre-Clinical Research and Translational Opportunities. Front Oncol (2014) 4:348. doi: 10.3389/ fonc.2014.00348

109. Lorenzo-Sanz L, Muñoz P. Tumor-Infiltrating Immunosuppressive Cells in Cancer-Cell Plasticity, Tumor Progression and Therapy Response. Cancer Microenviron (2019) 12(2-3):119-32. doi: 10.1007/s12307-019-00232-2

110. Zheng MM, Zhang Z, Bemis K, Belch AR, Pilarski LM, Shively JE, et al. The Systemic Cytokine Environment Is Permanently Altered in Multiple Myeloma. PloS One (2013) 8(3):e58504. doi: 10.1371/journal.pone.0058504

111. Corre J, Mahtouk K, Attal M, Gadelorge M, Huynh A, Fleury-Cappellesso S, et al. Bone Marrow Mesenchymal Stem Cells are Abnormal in Multiple Myeloma. Leuk Off J Leuk Soc Am Leuk Res Fund UK (2007) 21(5):1079-88. doi: $10.1038 /$ sj.leu. 2404621 
112. Garayoa M, Garcia JL, Santamaria C, Garcia-Gomez A, Blanco JF, Pandiella A, et al. Mesenchymal Stem Cells From Multiple Myeloma Patients Display Distinct Genomic Profile as Compared With Those From Normal Donors. Leukemia (2009) 23(8):1515-27. doi: 10.1038/leu.2009.65

113. de Jong MME, Kellermayer Z, Papazian N, Tahri S, Hofste op Bruinink D, Hoogenboezem R, et al. The Multiple Myeloma Microenvironment is Defined by an Inflammatory Stromal Cell Landscape. Nat Immunol (2021) 22(6):769-80. doi: 10.1038/s41590-021-00931-3

114. Fairfield H, Costa S, Falank C, Farrell M, Murphy CS, D’Amico A, et al. Multiple Myeloma Cells Alter Adipogenesis, Increase Senescence-Related and Inflammatory Gene Transcript Expression, and Alter Metabolism in Preadipocytes. Front Oncol (2021) 10:584683. doi: 10.3389/fonc.2020.584683

115. Adamik J, Galson DL, Roodman GD. Osteoblast Suppression in Multiple Myeloma Bone Disease. J Bone Oncol (2018) 13:62-70. doi: 10.1016/ j.jbo.2018.09.001

116. Trotter TN, Gibson JT, Sherpa TL, Gowda PS, Peker D, Yang Y. AdipocyteLineage Cells Support Growth and Dissemination of Multiple Myeloma in Bone. Am J Pathol (2016) 186(11):3054-63. doi: 10.1016/j.ajpath.2016.07.012

117. Giuliani N, Rizzoli V, Roodman GD. Multiple Myeloma Bone Disease: Pathophysiology of Osteoblast Inhibition. Blood (2006) 108(13):3992-6. doi: 10.1182/blood-2006-05-026112

118. Gooding S, Olechnowicz SWZ, Morris EV, Armitage AE, Arezes J, Frost J, et al. Transcriptomic Profiling of the Myeloma Bone-Lining Niche Reveals BMP Signalling Inhibition to Improve Bone Disease. Nat Commun (2019) 10 (1):4533. doi: 10.1038/s41467-019-12296-1

119. Hideshima T, Bergsagel PL, Kuehl WM, Anderson KC. Advances in Biology of Multiple Myeloma: Clinical Applications. Blood (2004) 104(3):607-18. doi: 10.1182/blood-2004-01-0037

120. Pagnucco G, Cardinale G, Gervasi F. Targeting Multiple Myeloma Cells and Their Bone Marrow Microenvironment. Ann NY Acad Sci (2004) 1028:3909. doi: 10.1196/annals.1322.047

121. Vacca A, Ribatti D, Roncali L, Ranieri G, Serio G, Silvestris F, et al. Bone Marrow Angiogenesis and Progression in Multiple Myeloma. Br J Haematol (1994) 87(3):503-8. doi: 10.1111/j.1365-2141.1994.tb08304.x

122. Vacca A, Ria R, Semeraro F, Merchionne F, Coluccia M, Boccarelli A, et al. Endothelial Cells in the Bone Marrow of Patients With Multiple Myeloma. Blood (2003) 102(9):3340-8. doi: 10.1182/blood-2003-04-1338

123. Berardi S, Caivano A, Ria R, Nico B, Savino R, Terracciano R, et al. Four Proteins Governing Overangiogenic Endothelial Cell Phenotype in Patients With Multiple Myeloma are Plausible Therapeutic Targets. Oncogene (2012) 31(18):2258-69. doi: 10.1038/onc.2011.412

124. Colla S, Storti P, Donofrio G, Todoerti K, Bolzoni M, Lazzaretti M, et al. Low Bone Marrow Oxygen Tension and Hypoxia-Inducible Factor- $1 \alpha$ Overexpression Characterize Patients With Multiple Myeloma: Role on the Transcriptional and Proangiogenic Profiles of CD138+ Cells. Leukemia (2010) 24(11):1967-70. doi: 10.1038/leu.2010.193

125. Wang AA, Gommerman JL, Rojas OL. Plasma Cells: From Cytokine Production to Regulation in Experimental Autoimmune Encephalomyelitis. J Mol Biol (2021) 433(1):166655. doi: 10.1016/ j.jmb.2020.09.014

126. Pioli PD. Plasma Cells, the Next Generation: Beyond Antibody Secretion. Front Immunol (2019) 10:2768. doi: 10.3389/fimmu.2019.02768

127. Dang VD, Hilgenberg E, Ries S, Shen P, Fillatreau S. From the Regulatory Functions of B Cells to the Identification of Cytokine-Producing Plasma Cell Subsets. Curr Opin Immunol (2014) 28:77-83. doi: 10.1016/j.coi.2014.02.009

128. De Vos J, Thykjaer T, Tarte K, Ensslen M, Raynaud P, Requirand G, et al. Comparison of Gene Expression Profiling Between Malignant and Normal Plasma Cells With Oligonucleotide Arrays. Oncogene (2002) 21(44):684857. doi: 10.1038/sj.onc. 1205868

129. Qian B, Pollard JW. Macrophage Diversity Enhances Tumor Progression and Metastasis. Cell (2010) 141(1):39-51. doi: 10.1016/j.cell.2010.03.014

130. Wang H, Hu WM, Xia Z J, Liang Y, Lu Y, Lin Sx, et al. High Numbers of CD163+ Tumor-Associated Macrophages Correlate With Poor Prognosis in Multiple Myeloma Patients Receiving Bortezomib-Based Regimens. J Cancer (2019) 10(14):3239-45. doi: 10.7150/jca.30102

131. Berardi S, Ria R, Reale A, De Luisi A, Catacchio I, Moschetta M, et al. Multiple Myeloma Macrophages: Pivotal Players in the Tumor Microenvironment. J Oncol (2013) 2013:183602. doi: 10.1155/2013/183602
132. Favaloro J, Liyadipitiya T, Brown R, Yang S, Suen H, Woodland N, et al. Myeloid Derived Suppressor Cells Are Numerically, Functionally and Phenotypically Different in Patients With Multiple Myeloma. Leuk Lymphoma (2014) 55(12):2893-900. doi: 10.3109/10428194.2014.904511

133. Lindau D, Gielen P, Kroesen M, Wesseling P, Adema GJ. The Immunosuppressive Tumour Network: Myeloid-Derived Suppressor Cells, Regulatory T Cells and Natural Killer T Cells. Immunol (2013) 138(2):10515. doi: $10.1111 /$ imm. 12036

134. Wang Z, Zhang L, Wang H, Xiong S, Li Y, Tao Q, et al. Tumor-Induced CD14+HLA-DR (-/Low) Myeloid-Derived Suppressor Cells Correlate With Tumor Progression and Outcome of Therapy in Multiple Myeloma Patients. Cancer Immunol Immunother CII (2015) 64(3):389-99. doi: 10.1007/s00262014-1646-4

135. Giallongo C, Tibullo D, Parrinello NL, La Cava P, Di Rosa M, Bramanti V, et al. Granulocyte-Like Myeloid Derived Suppressor Cells (G-MDSC) are Increased in Multiple Myeloma and Are Driven by Dysfunctional Mesenchymal Stem Cells (MSC). Oncotarget (2016) 7(52):85764-75. doi: 10.18632/oncotarget.7969

136. Hanson EM, Clements VK, Sinha P, Ilkovitch D, Ostrand-Rosenberg S. Myeloid-Derived Suppressor Cells Down-Regulate L-Selectin Expression on CD4+ and CD8+ T Cells. J Immunol Baltim Md 1950 (2009) 183(2):937-44. doi: 10.4049/jimmunol.0804253

137. Lu T, Ramakrishnan R, Altiok S, Youn JI, Cheng P, Celis E, et al. Tumor-Infiltrating Myeloid Cells Induce Tumor Cell Resistance to Cytotoxic T Cells in Mice. J Clin Invest (2011) 121(10):4015-29. doi: $10.1172 /$ JCI45862

138. Nausch N, Galani IE, Schlecker E, Cerwenka A. Mononuclear MyeloidDerived "Suppressor" Cells Express RAE-1 and Activate Natural Killer Cells. Blood (2008) 112(10):4080-9. doi: 10.1182/blood-2008-03-143776

139. Binsfeld M, Muller J, Lamour V, Veirman KD, Raeve HD, Bellahcène A, et al. Granulocytic Myeloid-Derived Suppressor Cells Promote Angiogenesis in the Context of Multiple Myeloma. Oncotarget (2016) 7(25):37931-43. doi: 10.18632/oncotarget.9270

140. Li H, Han Y, Guo Q, Zhang M, Cao X. Cancer-Expanded Myeloid-Derived Suppressor Cells Induce Anergy of NK Cells Through Membrane-Bound TGF-Beta 1. J Immunol Baltim Md 1950 (2009) 182(1):240-9. doi: 10.4049/ jimmunol.182.1.240

141. Stiff A, Trikha P, Mundy-Bosse B, McMichael E, Mace TA, Benner B, et al. Nitric Oxide Production by Myeloid-Derived Suppressor Cells Plays a Role in Impairing Fc Receptor-Mediated Natural Killer Cell Function. Clin Cancer Res Off J Am Assoc Cancer Res (2018) 24(8):1891-904. doi: 10.1158/10780432.CCR-17-0691

142. Wang JN, Cao XX, Zhao AL, Cai H, Wang X, Li J. Increased Activated Regulatory T Cell Subsets and Aging Treg-Like Cells in Multiple Myeloma and Monoclonal Gammopathy of Undetermined Significance: A Case Control Study. Cancer Cell Int (2018) 18:187. doi: 10.1186/s12935-018-0687-8

143. Muthu Raja KR, Rihova L, Zahradova L, Klincova M, Penka M, Hajek R. Increased T Regulatory Cells Are Associated With Adverse Clinical Features and Predict Progression in Multiple Myeloma. PloS One (2012) 7(10): e47077. doi: 10.1371/journal.pone.0047077

144. Prabhala RH, Neri P, Bae JE, Tassone P, Shammas MA, Allam CK, et al. Dysfunctional T Regulatory Cells in Multiple Myeloma. Blood (2006) 107 (1):301-4. doi: 10.1182/blood-2005-08-3101

145. Lad D, Huang Q, Hoeppli R, Garcia R, Xu L, Levings M, et al. Evaluating the Role of Tregs in the Progression of Multiple Myeloma. Leuk Lymphoma (2019) 60(9):2134-42. doi: 10.1080/10428194.2019.1579324

146. Braga WMT, Atanackovic D, Colleoni GWB. The Role of Regulatory T Cells and TH17 Cells in Multiple Myeloma. Clin Dev Immunol (2012) 2012:293479. doi: 10.1155/2012/293479

147. Prabhala RH, Pelluru D, Fulciniti M, Prabhala HK, Nanjappa P, Song W, et al. Elevated IL-17 Produced by Th17 Cells Promotes Myeloma Cell Growth and Inhibits Immune Function in Multiple Myeloma. Blood (2010) 115(26):5385-92. doi: 10.1182/blood-2009-10-246660

148. Bryant C, Suen H, Brown R, Yang S, Favaloro J, Aklilu E, et al. Long-Term Survival in Multiple Myeloma is Associated With a Distinct Immunological Profile, Which Includes Proliferative Cytotoxic T-Cell Clones and a Favourable Treg/Th17 Balance. Blood Cancer J (2013) 3(9):e148. doi: $10.1038 /$ bcj.2013.34 
149. Blom B, van Hoeven V, Hazenberg MD. ILCs in Hematologic Malignancies: Tumor Cell Killers and Tissue Healers. Semin Immunol (2019) 41:101279. doi: 10.1016/j.smim.2019.06.002

150. Carbone E, Neri P, Mesuraca M, Fulciniti MT, Otsuki T, Pende D, et al. HLA Class I, NKG2D, and Natural Cytotoxicity Receptors Regulate Multiple Myeloma Cell Recognition by Natural Killer Cells. Blood (2005) 105 (1):251-8. doi: 10.1182/blood-2004-04-1422

151. Lotzová E, Savary CA, Herberman RB. Inhibition of Clonogenic Growth of Fresh Leukemia Cells by Unstimulated and IL-2 Stimulated NK Cells of Normal Donors. Leuk Res (1987) 11(12):1059-66. doi: 10.1016/0145-2126 (87)90158-5

152. Frohn C, Höppner M, Schlenke P, Kirchner H, Koritke P, Luhm J. AntiMyeloma Activity of Natural Killer Lymphocytes. Br J Haematol (2002) 119 (3):660-4. doi: 10.1046/j.1365-2141.2002.03879.x

153. Stabile H, Fionda C, Gismondi A, Santoni A. Role of Distinct Natural Killer Cell Subsets in Anticancer Response. Front Immunol (2017) 8. doi: 10.3389/ fimmu.2017.00293

154. Lion E, Willemen Y, Berneman ZN, Van Tendeloo VFI, Smits ELJ. Natural Killer Cell Immune Escape in Acute Myeloid Leukemia. Leukemia (2012) 26 (9):2019-26. doi: 10.1038/leu.2012.87

155. Jurisic V, Srdic T, Konjevic G, Markovic O, Colovic M. Clinical StageDepending Decrease of NK Cell Activity in Multiple Myeloma Patients. Med Oncol Northwood Lond Engl (2007) 24(3):312-7. doi: 10.1007/s12032-0070007-y

156. Pittari G, Vago L, Festuccia M, Bonini C, Mudawi D, Giaccone L, et al. Restoring Natural Killer Cell Immunity Against Multiple Myeloma in the Era of New Drugs. Front Immunol (2017) 8. doi: 10.3389/fimmu.2017.01444

157. Carlsten M, Järås M. Natural Killer Cells in Myeloid Malignancies: Immune Surveillance, NK Cell Dysfunction, and Pharmacological Opportunities to Bolster the Endogenous NK Cells. Front Immunol (2019) 10. doi: 10.3389/ fimmu.2019.02357

158. El-Sherbiny YM, Meade JL, Holmes TD, McGonagle D, Mackie SL, Morgan AW, et al. The Requirement for DNAM-1, NKG2D, and NKp46 in the Natural Killer Cell-Mediated Killing of Myeloma Cells. Cancer Res (2007) 67 (18):8444-9. doi: 10.1158/0008-5472.CAN-06-4230

159. García-Sanz R, González M, Orfão A, Moro MJ, Hernández JM, Borrego D, et al. Analysis of Natural Killer-Associated Antigens in Peripheral Blood and Bone Marrow of Multiple Myeloma Patients and Prognostic Implications. Br J Haematol (1996) 93(1):81-8. doi: 10.1046/j.1365-2141.1996.4651006.x

160. Farnault L, Sanchez C, Baier C, Le Treut T, Costello RT. Hematological Malignancies Escape From NK Cell Innate Immune Surveillance: Mechanisms and Therapeutic Implications. Clin Dev Immunol (2012) 2012:e421702. doi: 10.1155/2012/421702

161. Nersesian S, Schwartz SL, Grantham SR, MacLean LK, Lee SN, Pugh-Toole $\mathrm{M}$, et al. NK Cell Infiltration is Associated With Improved Overall Survival in Solid Cancers: A Systematic Review and Meta-Analysis. Transl Oncol (2021) 14(1):100930. doi: 10.1016/j.tranon.2020.100930

162. Giles AJ, Chien CD, Reid CM, Fry TJ, Park DM, Kaplan RN, et al. The Functional Interplay Between Systemic Cancer and the Hematopoietic Stem Cell Niche. Pharmacol Ther (2016) 168:53-60. doi: 10.1016/ j.pharmthera.2016.09.006

163. Famularo G, D’Ambrosio A, Quintieri F, Di Giovanni S, Parzanese I, Pizzuto F, et al. Natural Killer Cell Frequency and Function in Patients With Monoclonal Gammopathies. J Clin Lab Immunol (1992) 37 (3):99-109.

164. Osterborg A, Nilsson B, Björkholm M, Holm G, Mellstedt H. Natural Killer Cell Activity in Monoclonal Gammopathies: Relation to Disease Activity. Eur J Haematol (1990) 45(3):153-7. doi: 10.1111/j.1600-0609.1990.tb00443.x

165. Pazina T, MacFarlane AW, Bernabei L, Dulaimi E, Kotcher R, Yam C, et al. Alterations of NK Cell Phenotype in the Disease Course of Multiple Myeloma. Cancers (2021) 13(2):226. doi: 10.3390/cancers13020226

166. Duault C, Kumar A, Taghi Khani A, Lee SJ, Yang L, Huang M, et al. Activated Natural Killer Cells Predict Poor Clinical Prognosis in High-Risk B- and T-Cell Acute Lymphoblastic Leukemia. Blood (2021) 138(16):146580. doi: 10.1182/blood.2020009871

167. Riggan L, Shah S, O'Sullivan TE. Arrested Development: Suppression of NK Cell Function in the Tumor Microenvironment. Clin Transl Immunol (2021) 10(1):e1238. doi: 10.1002/cti2.1238
168. Bi J, Wang X. Molecular Regulation of NK Cell Maturation. Front Immunol (2020) 11. doi: 10.3389/fimmu.2020.01945

169. Miraki-Moud F, Anjos-Afonso F, Hodby KA, Griessinger E, Rosignoli G, Lillington D, et al. Acute Myeloid Leukemia Does Not Deplete Normal Hematopoietic Stem Cells But Induces Cytopenias by Impeding Their Differentiation. Proc Natl Acad Sci USA (2013) 110(33):13576-81. doi: $10.1073 /$ pnas.1301891110

170. Richards JO, Chang X, Blaser BW, Caligiuri MA, Zheng P, Liu Y. Tumor Growth Impedes Natural-Killer-Cell Maturation in the Bone Marrow. Blood (2006) 108(1):246-52. doi: 10.1182/blood-2005-11-4535

171. Wang X, Zhao XY. Transcription Factors Associated With IL-15 Cytokine Signaling During NK Cell Development. Front Immunol (2021) 12:610789. doi: 10.3389/fimmu.2021.610789

172. Gotthardt D, Trifinopoulos J, Sexl V, Putz EM. JAK/STAT Cytokine Signaling at the Crossroad of NK Cell Development and Maturation. Front Immunol (2019) 10:2590. doi: 10.3389/fimmu.2019.02590

173. Wang Y, Gao A, Zhao H, Lu P, Cheng H, Dong F, et al. Leukemia Cell Infiltration Causes Defective Erythropoiesis Partially Through MIP-1 $\alpha / \mathrm{Ccl} 3$. Leukemia (2016) 30(9):1897-908. doi: 10.1038/leu.2016.81

174. Orange JS. Natural Killer Cell Deficiency. J Allergy Clin Immunol (2013) 132 (3):515-25. doi: 10.1016/j.jaci.2013.07.020

175. Joshi PC, Zhou X, Cuchens M, Jones Q. Prostaglandin E2 Suppressed IL-15Mediated Human NK Cell Function Through Down-Regulation of Common Gamma-Chain. J Immunol Baltim Md 1950 (2001) 166(2):885-91. doi: 10.4049/jimmunol.166.2.885

176. Mishra HK, Dixon KJ, Pore N, Felices M, Miller JS, Walcheck B. Activation of ADAM17 by IL-15 Limits Human NK Cell Proliferation. Front Immunol (2021) 12:711621. doi: 10.3389/fimmu.2021.711621

177. Felices M, Lenvik AJ, McElmurry R, et al. Continuous Treatment With IL-15 Exhausts Human NK Cells via a Metabolic Defect. JCI Insight (2018) 3 (3):96219. doi: 10.1172/jci.insight.96219

178. Bębnowska D, Hrynkiewicz R, Grywalska E, Pasiarski M, SosnowskaPasiarska B, Smarz-Widelska I, et al. Immunological Prognostic Factors in Multiple Myeloma. Int J Mol Sci (2021) 22(7):3587. doi: 10.3390/ ijms 22073587

179. Vacca A, Di Stefano R, Frassanito A, Iodice G, Dammacco F. A Disturbance of the IL-2/IL-2 Receptor System Parallels the Activity of Multiple Myeloma. Clin Exp Immunol (1991) 84(3):429-34.

180. Kotlarz D, Ziętara N, Uzel G, Weidemann T, Braun CJ, Diestelhorst J, et al. Loss-Of-Function Mutations in the IL-21 Receptor Gene Cause a Primary Immunodeficiency Syndrome. J Exp Med (2013) 210(3):433-43. doi: 10.1084/jem.20111229

181. Brady J, Hayakawa Y, Smyth MJ, Nutt SL. IL-21 Induces the Functional Maturation of Murine NK Cells. J Immunol (2004) 172(4):2048-58. doi: 10.4049/jimmunol.172.4.2048

182. Habib T, Nelson A, Kaushansky K. IL-21: A Novel IL-2-Family Lymphokine That Modulates B, T, and Natural Killer Cell Responses. J Allergy Clin Immunol (2003) 112(6):1033-45. doi: 10.1016/j.jaci.2003.08.039

183. Nair S, Fang M, Sigal LJ. The Natural Killer Cell Dysfunction of Aged Mice is Due to the Bone Marrow Stroma and Is Not Restored by IL-15/IL-15ro Treatment. Aging Cell (2015) 14(2):180-90. doi: 10.1111/acel.12291

184. Pedroza-Pacheco I, Shah D, Domogala A, Luevano M, Blundell M, Jackson $\mathrm{N}$, et al. Regulatory T Cells Inhibit CD34+ Cell Differentiation Into NK Cells by Blocking Their Proliferation. Sci Rep (2016) 6:22097. doi: 10.1038/ srep22097

185. Marcoe JP, Lim JR, Schaubert KL, et al. TGF- $\beta$ is Responsible for NK Cell Immaturity During Ontogeny and Increased Susceptibility to Infection During Mouse Infancy. Nat Immunol (2012) 13(9):843-50. doi: 10.1038/ ni.2388

186. Rolston KVI. Infections in Cancer Patients With Solid Tumors: A Review. Infect Dis Ther (2017) 6(1):69-83. doi: 10.1007/s40121-017-0146-1

187. Nucci M, Anaissie E. Infections in Patients With Multiple Myeloma in the Era of High-Dose Therapy and Novel Agents. Clin Infect Dis Off Publ Infect Dis Soc Am (2009) 49(8):1211-25. doi: 10.1086/605664

188. Zhang S, Liu W, Hu B, Wang P, Lv X, Chen S, et al. Prognostic Significance of Tumor-Infiltrating Natural Killer Cells in Solid Tumors: A Systematic Review and Meta-Analysis. Front Immunol (2020) 11:1242. doi: 10.3389/ fimmu.2020.01242 
189. Bernardini G, Antonangeli F, Bonanni V, Santoni A. Dysregulation of Chemokine/Chemokine Receptor Axes and NK Cell Tissue Localization During Diseases. Front Immunol (2016) 7:402. doi: 10.3389/fimmu. 2016.00402

190. Walzer T, Chiossone L, Chaix J, Calver A, Carozzo C, Garrigue-Antar L, et al. Natural Killer Cell Trafficking In Vivo Requires a Dedicated Sphingosine 1Phosphate Receptor. Nat Immunol (2007) 8(12):1337-44. doi: 10.1038/ ni1523

191. Bernardini G, Sciumè G, Bosisio D, Morrone S, Sozzani S, Santoni A. CCL3 and CXCL12 Regulate Trafficking of Mouse Bone Marrow NK Cell Subsets. Blood (2008) 111(7):3626-34. doi: 10.1182/blood-2007-08-106203

192. Mayol K, Biajoux V, Marvel J, Balabanian K, Walzer T. Sequential Desensitization of CXCR4 and S1P5 Controls Natural Killer Cell Trafficking. Blood (2011) 118(18):4863-71. doi: 10.1182/blood-2011-06362574

193. Ponzetta A, Benigni G, Antonangeli F, Sciumè G, Sanseviero E, Zingoni A, et al. Multiple Myeloma Impairs Bone Marrow Localization of Effector Natural Killer Cells by Altering the Chemokine Microenvironment. Cancer Res (2015) 75(22):4766-77. doi: 10.1158/0008-5472.CAN-15-1320

194. Lim SA, Kim J, Jeon S, Shin MH, Kwon J, Kim TJ, et al. Defective Localization With Impaired Tumor Cytotoxicity Contributes to the Immune Escape of NK Cells in Pancreatic Cancer Patients. Front Immunol (2019) 10:496. doi: 10.3389/fimmu.2019.00496

195. Yao X, Matosevic S. Chemokine Networks Modulating Natural Killer Cell Trafficking to Solid Tumors. Cytokine Growth Factor Rev (2021) 59:36-45. doi: 10.1016/j.cytogfr.2020.12.003

196. Pellegrino A, Antonaci F, Russo F, Merchionne F, Ribatti D, Vacca A, et al. CXCR3-Binding Chemokines in Multiple Myeloma. Cancer Lett (2004) 207 (2):221-7. doi: 10.1016/j.canlet.2003.10.036

197. Bolomsky A, Schreder M, Hübl W, Zojer N, Hilbe W, Ludwig H. Monokine Induced by Interferon Gamma (MIG/CXCL9) Is an Independent Prognostic Factor in Newly Diagnosed Myeloma. Leuk Lymphoma (2016) 57(11):251625. doi: 10.3109/10428194.2016.1151511

198. Bonanni V, Antonangeli F, Santoni A, Bernardini G. Targeting of CXCR3 Improves Anti-Myeloma Efficacy of Adoptively Transferred Activated Natural Killer Cells. J Immunother Cancer (2019) 7(1):290. doi: 10.1186/ s40425-019-0751-5

199. Nobutani K, Shimono Y, Mizutani K, Ueda Y, Suzuki T, Kitayama M, et al. Downregulation of CXCR4 in Metastasized Breast Cancer Cells and Implication in Their Dormancy. PloS One (2015) 10(6):e0130032. doi: 10.1371/journal.pone.0130032

200. Bernardini G, Sciumè G, Santoni A. Differential Chemotactic Receptor Requirements for NK Cell Subset Trafficking Into Bone Marrow. Front Immunol (2013) 4:12. doi: 10.3389/fimmu.2013.00012

201. Noda M, Omatsu Y, Sugiyama T, Oishi S, Fujii N, Nagasawa T. CXCL12-CXCR4 Chemokine Signaling Is Essential for NK-Cell Development in Adult Mice. Blood (2011) 117(2):451-8. doi: 10.1182/ blood-2010-04-277897

202. Kohli K, Pillarisetty VG, Kim TS. Key Chemokines Direct Migration of Immune Cells in Solid Tumors. Cancer Gene Ther (2021). doi: 10.1038/ s41417-021-00303-x

203. Lesokhin AM, Bal S, Badros AZ. Lessons Learned From Checkpoint Blockade Targeting PD-1 in Multiple Myeloma. Cancer Immunol Res (2019) 7(8):1224-9. doi: 10.1158/2326-6066.CIR-19-0148

204. Okazaki T, Honjo T. PD-1 and PD-1 Ligands: From Discovery to Clinical Application. Int Immunol (2007) 19(7):813-24. doi: 10.1093/intimm/ dxm057

205. Rosenblatt J, Avigan D. Targeting the PD-1/PD-L1 Axis in Multiple Myeloma: A Dream or a Reality? Blood (2017) 129(3):275-9. doi: 10.1182/ blood-2016-08-731885

206. Quatrini L, Mariotti FR, Munari E, Tumino N, Vacca P, Moretta L. The Immune Checkpoint PD-1 in Natural Killer Cells: Expression, Function and Targeting in Tumour Immunotherapy. Cancers (2020) 12(11):E3285. doi: $10.3390 /$ cancers 12113285

207. Lee BH, Park Y, Kim JH, Kang KW, Lee SJ, Kim SJ, et al. PD-L1 Expression in Bone Marrow Plasma Cells as a Biomarker to Predict Multiple Myeloma Prognosis: Developing a Nomogram-Based Prognostic Model. Sci Rep (2020) 10(1):12641. doi: 10.1038/s41598-020-69616-5
208. Tamura H, Ishibashi M, Sunakawa-Kii M, Inokuchi K. PD-L1-PD-1 Pathway in the Pathophysiology of Multiple Myeloma. Cancers (2020) 12 (4):924. doi: 10.3390/cancers12040924

209. Benson DM, Bakan CE, Mishra A, Hofmeister CC, Efebera Y, Becknell B, et al. The PD-1/PD-L1 Axis Modulates the Natural Killer Cell Versus Multiple Myeloma Effect: A Therapeutic Target for CT-011, a Novel Monoclonal Anti-PD-1 Antibody. Blood (2010) 116(13):2286-94. doi: 10.1182/blood-2010-02-271874

210. Carter L, Fouser LA, Jussif J, Fitz L, Deng B, Wood CR, et al. PD-1:PD-L Inhibitory Pathway Affects Both CD4(+) and CD8(+) T Cells and Is Overcome by IL-2. Eur J Immunol (2002) 32(3):634-43. doi: 10.1002/ 1521-4141(200203)32:3<634::AID-IMMU634>3.0.CO;2-9

211. Davis Z, Felices M, Lenvik TR, Badal S, Hinderlie P, Blazar BR, et al. PD-1 Is Expressed at Low Levels on All Peripheral Blood Natural Killer Cells But Is a Significant Suppressor of NK Function Against PD-1 Ligand Expressing Tumor Targets. Blood (2019) 134(Supplement_1):621-1. doi: 10.1182/blood2019-127261

212. Liu Y, Cheng Y, Xu Y, Wang Z, Du X, Li C, et al. Increased Expression of Programmed Cell Death Protein 1 on NK Cells Inhibits NK-Cell-Mediated Anti-Tumor Function and Indicates Poor Prognosis in Digestive Cancers. Oncogene (2017) 36(44):6143-53. doi: 10.1038/onc.2017.209

213. Laba S, Mallett G, Amarnath S. The Depths of PD-1 Function Within the Tumor Microenvironment Beyond CD8+ T Cells. Semin Cancer Biol (2021) S1044-579X(21):00153-X. doi: 10.1016/j.semcancer.2021.05.022 Published online May 25.

214. Iwata T, Kondo Y, Kimura O, Morosawa T, Fujisaka Y, Umetsu T, et al. PDL1+MDSCs are Increased in HCC Patients and Induced by Soluble Factor in the Tumor Microenvironment. Sci Rep (2016) 6:39296. doi: 10.1038/ srep39296

215. Lu C, Redd PS, Lee JR, Savage N, Liu K. The Expression Profiles and Regulation of PD-L1 in Tumor-Induced Myeloid-Derived Suppressor Cells. OncoImmunol (2016) 5(12):e1247135. doi: 10.1080/2162402X.2016. 1247135

216. Tamura H, Ishibashi M, Yamashita T, Tanosaki S, Okuyama N, Kondo A, et al. Marrow Stromal Cells Induce B7-H1 Expression on Myeloma Cells, Generating Aggressive Characteristics in Multiple Myeloma. Leukemia (2013) 27(2):464-72. doi: 10.1038/leu.2012.213

217. Chen H, Li M, Sanchez E, Soof CM, Bujarski S, Ng N, et al. The JAK Inhibitor Blocks PD-L1, PD-L2 and CD44 Expression in Multiple Myeloma (MM) and Sensitizes MM Cells to Lenalidomide and Steroids. Blood (2018) 132 (Supplement 1):1910. doi: 10.1182/blood-2018-99-119099

218. Lee YS, Choi H, Cho HR, Son WC, Park YS, Kang CD, et al. Downregulation of NKG2DLs by TGF- $\beta$ in Human Lung Cancer Cells. BMC Immunol (2021) 22(1):44. doi: 10.1186/s12865-021-00434-8

219. Kinter AL, Godbout EJ, McNally JP, Sereti I, Roby GA, O'Shea MA, et al. The Common Gamma-Chain Cytokines IL-2, IL-7, IL-15, and IL-21 Induce the Expression of Programmed Death-1 and its Ligands. J Immunol Baltim Md 1950 (2008) 181(10):6738-46. doi: 10.4049/jimmunol.181.10.6738

220. Park IH, Yang HN, Lee KJ, Kim TS, Lee ES, Jung SY, et al. Tumor-Derived IL-18 Induces PD-1 Expression on Immunosuppressive NK Cells in TripleNegative Breast Cancer. Oncotarget (2017) 8(20):32722-30. doi: 10.18632/ oncotarget.16281

221. Terawaki S, Chikuma S, Shibayama S, Hayashi T, Yoshida T, Okazaki T, et al. IFN- $\alpha$ Directly Promotes Programmed Cell Death-1 Transcription and Limits the Duration of T Cell-Mediated Immunity. J Immunol Baltim Md 1950 (2011) 186(5):2772-9. doi: 10.4049/jimmunol.1003208

222. Noman MZ, Desantis G, Janji B, Hasmim M, Karray S, Dessen P, et al. PDL1 Is a Novel Direct Target of HIF-1 $\alpha$, and its Blockade Under Hypoxia Enhanced MDSC-Mediated T Cell Activation. J Exp Med (2014) 211(5):78190. doi: 10.1084/jem.20131916

223. Cluff ER, Nolan J, Collins C, Varadaraj A, Rajasekaran N. Hypoxia-Inducible Factor- $1 \alpha$ is Upregulated in Natural Killer Cells by Interleukin- 2 and Hypoxia via PI3K/mTOR Signaling Pathway. J Immunol (2019) 202(1 Supplement):194.37-7.

224. Sun C, Xu J, Huang Q, Huang M, Wen H, Zhang C, et al. High NKG2A Expression Contributes to NK Cell Exhaustion and Predicts a Poor Prognosis of Patients With Liver Cancer. OncoImmunol (2016) 6(1): e1264562. doi: 10.1080/2162402X.2016.1264562 
225. Gooden M, Lampen M, Jordanova ES, Leffers N, Trimbos JB, van der Burg SH, et al. HLA-E Expression by Gynecological Cancers Restrains TumorInfiltrating $\mathrm{CD}^{+}$T Lymphocytes. Proc Natl Acad Sci USA (2011) 108 (26):10656-61. doi: 10.1073/pnas.1100354108

226. Benevolo M, Mottolese M, Tremante E, Rollo F, Diodoro MG, Ercolani C, et al. High Expression of HLA-E in Colorectal Carcinoma Is Associated With a Favorable Prognosis. J Transl Med (2011) 9:184. doi: 10.1186/1479-5876-9184

227. Mahaweni NM, Ehlers FAI, Sarkar S, Janssen JWH, Tilanus MGJ, Bos GMJ, et al. NKG2A Expression Is Not Per Se Detrimental for the Anti-Multiple Myeloma Activity of Activated Natural Killer Cells in an In Vitro System Mimicking the Tumor Microenvironment. Front Immunol (2018) 9:1415. doi: 10.3389/fimmu.2018.01415

228. Kamiya T, Seow SV, Wong D, Robinson M, Campana D. Blocking Expression of Inhibitory Receptor NKG2A Overcomes Tumor Resistance to NK Cells. J Clin Invest (2019) 129(5):2094-106. doi: 10.1172/JCI123955

229. Ruggeri L, Urbani E, André P, Mancusi A, Tosti A, Topini F, et al. Effects of Anti-NKG2A Antibody Administration on Leukemia and Normal Hematopoietic Cells. Haematologica (2016) 101(5):626-33. doi: 10.3324/ haematol.2015.135301

230. Yang Y, Liu Z, Wang H, Zhang G. HLA-E Binding Peptide as a Potential Therapeutic Candidate for High-Risk Multiple Myeloma. Front Oncol (2021) 11:670673. doi: $10.3389 /$ fonc.2021.670673

231. Malmberg KJ, Levitsky V, Norell H, de Matos CT, Carlsten M, Schedvins K, et al. IFN-Gamma Protects Short-Term Ovarian Carcinoma Cell Lines From CTL Lysis via a CD94/NKG2A-Dependent Mechanism. J Clin Invest (2002) 110(10):1515-23. doi: 10.1172/JCI15564

232. Marchesi M, Andersson E, Villabona L, Seliger B, Lundqvist A, Kiessling R, et al. HLA-Dependent Tumour Development: A Role for Tumour Associate Macrophages? J Transl Med (2013) 11:247. doi: 10.1186/1479-5876-11-247

233. Bertone S, Schiavetti F, Bellomo R, Vitale C, Ponte M, Moretta L, et al. Transforming Growth Factor-Beta-Induced Expression of CD94/NKG2A Inhibitory Receptors in Human T Lymphocytes. Eur J Immunol (1999) 29 (1):23-9. doi: 10.1002/(SICI) 1521-4141(199901)29:01<23::AIDIMMU23>3.0.CO;2-Y

234. Hromadnikova I, Pirkova P, Sedlackova L. Influence of In Vitro IL-2 or IL-15 Alone or in Combination With Hsp-70-Derived 14-Mer Peptide (TKD) on the Expression of NK Cell Activatory and Inhibitory Receptors. Mediators Inflamm (2013) 2013:405295. doi: 10.1155/2013/405295

235. Jonges LE, Giezeman-Smits KM, van Vlierberghe RL, Ensink NG, Hagenaars M, Joly E, et al. NK Cells Modulate MHC Class I Expression on Tumor Cells and Their Susceptibility to Lysis. Immunobiology (2000) 202(4):326-38. doi: 10.1016/s0171-2985(00)80037-6

236. Cornel AM, Mimpen IL, Nierkens S. MHC Class I Downregulation in Cancer: Underlying Mechanisms and Potential Targets for Cancer Immunotherapy. Cancers (2020) 12(7):1760. doi: 10.3390/cancers12071760

237. Gao M, Gao L, Yang G, Tao Y, Hou J, Xu H, et al. Myeloma Cells Resistance to NK Cell Lysis Mainly Involves an HLA Class I-Dependent Mechanism. Acta Biochim Biophys Sin (2014) 46(7):597-604. doi: 10.1093/abbs/gmu041

238. Martínez-Sánchez MV, Periago A, Legaz I, Gimeno L, Mrowiec A, MontesBarqueros NR, et al. Overexpression of KIR Inhibitory Ligands (HLA-I) Determines That Immunosurveillance of Myeloma Depends on Diverse and Strong NK Cell Licensing. OncoImmunol (2015) 5(4):e1093721. doi: 10.1080/ 2162402X.2015.1093721

239. Sarkar S, van Gelder M, Noort W, Xu Y, Rouschop KMA, Groen R, et al. Optimal Selection of Natural Killer Cells to Kill Myeloma: The Role of HLA$\mathrm{E}$ and NKG2A. Cancer Immunol Immunother CII (2015) 64(8):951-63. doi: 10.1007/s00262-015-1694-4

240. Mahaweni NM, Ehlers FAI, Bos GMJ, Wieten L. Tuning Natural Killer Cell Anti-Multiple Myeloma Reactivity by Targeting Inhibitory Signaling via KIR and NKG2A. Front Immunol (2018) 9:2848. doi: 10.3389/fimmu.2018.02848

241. Ruggeri L, Capanni M, Urbani E, Perruccio K, Shlomchik WD, Tosti A, et al. Effectiveness of Donor Natural Killer Cell Alloreactivity in Mismatched Hematopoietic Transplants. Science (2002) 295(5562):2097-100. doi: $10.1126 /$ science. 1068440

242. Felices M, Miller JS. Targeting KIR Blockade in Multiple Myeloma: Trouble in Checkpoint Paradise? Clin Cancer Res OffJ Am Assoc Cancer Res (2016) 22 (21):5161-3. doi: 10.1158/1078-0432.CCR-16-1582
243. Ewen EM, Pahl JHW, Miller M, Watzl C, Cerwenka A. KIR Downregulation by IL-12/15/18 Unleashes Human NK Cells From KIR/HLA-I Inhibition and Enhances Killing of Tumor Cells. Eur J Immunol (2018) 48(2):355-65. doi: $10.1002 /$ eji.201747128

244. Berglund AK, Fisher MB, Cameron KA, Poole EJ, Schnabel LV. Transforming Growth Factor- $\beta 2$ Downregulates Major Histocompatibility Complex (MHC) I and MHC II Surface Expression on Equine Bone Marrow-Derived Mesenchymal Stem Cells Without Altering Other Phenotypic Cell Surface Markers. Front Vet Sci (2017) 4:84. doi: 10.3389/ fvets.2017.00084

245. Harjunpää H, Guillerey C. TIGIT as an Emerging Immune Checkpoint. Clin Exp Immunol (2020) 200(2):108-19. doi: 10.1111/cei.13407

246. Lozano E, Mena MP, Díaz T, Martin-Antonio B, León S, Rodríguez-Lobato LG, et al. Nectin-2 Expression on Malignant Plasma Cells Is Associated With Better Response to TIGIT Blockade in Multiple Myeloma. Clin Cancer Res Off J Am Assoc Cancer Res (2020) 26(17):4688-98. doi: 10.1158/10780432.CCR-19-3673

247. Stamm H, Wellbrock J, Fiedler W. Interaction of PVR/PVRL2 With TIGIT/ DNAM-1 as a Novel Immune Checkpoint Axis and Therapeutic Target in Cancer. Mamm Genome Off I Int Mamm Genome Soc (2018) 29(11-12):694702. doi: 10.1007/s00335-018-9770-7

248. Guillerey C, Harjunpää H, Carrié N, Kassem S, Teo T, Miles K, et al. TIGIT Immune Checkpoint Blockade Restores CD8+ T-Cell Immunity Against Multiple Myeloma. Blood (2018) 132(16):1689-94. doi: 10.1182/blood-201801-825265

249. Mekhloufi A, Kosta A, Stabile H, Molfetta R, Zingoni A, Soriani A, et al. Bone Marrow Stromal Cell-Derived IL-8 Upregulates PVR Expression on Multiple Myeloma Cells. via NF-kB Transcription Factor Cancers (2020) 12(2):E440. doi: $10.3390 /$ cancers 12020440

250. Sarhan D, Cichocki F, Zhang B, Yingst A, Spellman SR, Cooley S, et al. Adaptive NK Cells With Low TIGIT Expression Are Inherently Resistant to Myeloid-Derived Suppressor Cells. Cancer Res (2016) 76(19):5696-706. doi: 10.1158/0008-5472.CAN-16-0839

251. Dao TN, Utturkar S, Atallah Lanman N, Matosevic S. TIM-3 Expression Is Downregulated on Human NK Cells in Response to Cancer Targets in Synergy With Activation. Cancers (2020) 12(9):E2417. doi: 10.3390/ cancers 12092417

252. Liu Z, Xiang C, Han M, Meng N, Luo J, Fu R. Study on Tim3 Regulation of Multiple Myeloma Cell Proliferation via NF-kb Signal Pathways. Front Oncol (2020) 10:584530. doi: 10.3389/fonc.2020.584530

253. Fourcade J, Sun Z, Benallaoua M, Guillaume P, Luescher IF, Sander C, et al. Upregulation of Tim-3 and PD-1 Expression Is Associated With Tumor Antigen-Specific CD8+ T Cell Dysfunction in Melanoma Patients. J Exp Med (2010) 207(10):2175-86. doi: 10.1084/jem.20100637

254. Fu RJr, Ding S, Liu C, Liu B, Liu H, Zhaoyun L, et al. The Role of Decreased TIM-3 Expression of Natural Killer Cells in the Immune Pathogenesis of Severe Aplastic Anemia. Blood (2019) 134(Supplement_1):3747. doi: 10.1182/blood-2019-127769

255. Golden-Mason L, McMahan RH, Strong M, Reisdorph R, Mahaffey S, Palmer BE, et al. Galectin-9 Functionally Impairs Natural Killer Cells in Humans and Mice. J Virol (2013) 87(9):4835-45. doi: 10.1128/JVI.01085-12

256. Xu J, Liu B, Ma S, Zhang J, Ji Y, Xu L, et al. Characterizing the Tumor Suppressor Role of CEACAM1 in Multiple Myeloma. Cell Physiol Biochem Int J Exp Cell Physiol Biochem Pharmacol (2018) 45(4):1631-40. doi: $10.1159 / 000487730$

257. Ning J, Yang R, Wang H, Cui L. HMGB1 Enhances Chemotherapy Resistance in Multiple Myeloma Cells by Activating the Nuclear Factor- $\mathrm{kb}$ Pathway. Exp Ther Med (2021) 22(1):705. doi: 10.3892/etm.2021.10137

258. Bednarek K, Kostrzewska-Poczekaj M, Szaumkessel M, Kiwerska K, Paczkowska J, Byzia E, et al. Downregulation of CEACAM6 Gene Expression in Laryngeal Squamous Cell Carcinoma Is an Effect of DNA Hypermethylation and Correlates With Disease Progression. Am J Cancer Res (2018) 8(7):1249-61.

259. Fauriat C, Mallet F, Olive D, Costello RT. Impaired Activating Receptor Expression Pattern in Natural Killer Cells From Patients With Multiple Myeloma. Leukemia (2006) 20(4):732-3. doi: 10.1038/sj.leu.2404096

260. Sanchez-Correa B, Morgado S, Gayoso I, Bergua JM, Casado JG, Arcos MJ, et al. Human NK Cells in Acute Myeloid Leukaemia Patients: Analysis of NK 
Cell-Activating Receptors and Their Ligands. Cancer Immunol Immunother (2011) 60(8):1195-205. doi: 10.1007/s00262-011-1050-2

261. Costello RT, Boehrer A, Sanchez C, Mercier D, Baier C, Treut T, et al. Differential Expression of Natural Killer Cell Activating Receptors in Blood Versus Bone Marrow in Patients With Monoclonal Gammopathy. Immunol (2013) 139(3):338-41. doi: 10.1111/imm.12082

262. Raulet DH. Roles of the NKG2D Immunoreceptor and its Ligands. Nat Rev Immunol (2003) 3(10):781-90. doi: 10.1038/nri1199

263. Song H, Kim J, Cosman D, Choi I. Soluble ULBP Suppresses Natural Killer Cell Activity via Down-Regulating NKG2D Expression. Cell Immunol (2006) 239(1):22-30. doi: 10.1016/j.cellimm.2006.03.002

264. Lundholm M, Schröder M, Nagaeva O, Baranov V, Widmark A, MinchevaNilsson L, et al. Prostate Tumor-Derived Exosomes Down-Regulate NKG2D Expression on Natural Killer Cells and CD8+ T Cells: Mechanism of Immune Evasion. PloS One (2014) 9(9):e108925. doi: 10.1371/journal. pone. 0108925

265. Groh V, Wu J, Yee C, Spies T. Tumour-Derived Soluble MIC Ligands Impair Expression of NKG2D and T-Cell Activation. Nat (2002) 419(6908):734-8. doi: 10.1038 /nature 01112

266. Deng W, Gowen BG, Zhang L, et al. A Shed NKG2D Ligand That Promotes Natural Killer Cell Activation and Tumor Rejection. Sci (2015) 348 (6230):136-9. doi: 10.1126/science.1258867

267. Krockenberger M, Dombrowski Y, Weidler C, Ossadnik M, Hönig A, Häusler S, et al. Macrophage Migration Inhibitory Factor (MIF) Contributes to the Immune Escape of Ovarian Cancer by Downregulating NKG2D. J Immunol Baltim Md 1950 (2008) 180(11):7338-48.

268. Zhang J, Han X, Hu X, Jin F, Gao Z, Yin L, et al. IDO1 Impairs NK Cell Cytotoxicity by Decreasing NKG2D/NKG2DLs. via promoting miR-18a Mol Immunol (2018) 103:144-55. doi: 10.1016/j.molimm.2018.09.011

269. Leivas A, Valeri A, Córdoba L, García-Ortiz A, Ortiz A, Sánchez-Vega L, et al. NKG2D-CAR-Transduced Natural Killer Cells Efficiently Target Multiple Myeloma. Blood Cancer J (2021) 11(8):146. doi: 10.1038/s41408021-00537-w

270. Hsi ED, Steinle R, Balasa B, Szmania S, Draksharapu A, Shum BP, et al. CS1, a Potential New Therapeutic Antibody Target for the Treatment of Multiple Myeloma. Clin Cancer Res Off J Am Assoc Cancer Res (2008) 14(9):2775-84. doi: 10.1158/1078-0432.CCR-07-4246

271. Veillette A, Guo H. CS1, a SLAM Family Receptor Involved in Immune Regulation, Is a Therapeutic Target in Multiple Myeloma. Crit Rev Oncol Hematol (2013) 88(1):168-77. doi: 10.1016/j.critrevonc.2013.04.003

272. Kikuchi J, Hori M, Iha H, Toyama-Sorimachi N, Hagiwara S, Kuroda Y, et al. Soluble SLAMF7 Promotes the Growth of Myeloma Cells via Homophilic Interaction With Surface SLAMF7. Leukemia (2020) 34(1):180-95. doi: 10.1038/s41375-019-0525-6

273. Ishibashi M, Soeda S, Sasaki M, Handa H, Imai Y, Tanaka N, et al. Clinical Impact of Serum Soluble SLAMF7 in Multiple Myeloma. Oncotarget (2018) 9 (78):34784-93. doi: 10.18632/oncotarget.26196

274. Dimopoulos MA, Lonial S, Betts KA, Chen C, Zichlin ML, Brun A, et al. Elotuzumab Plus Lenalidomide and Dexamethasone in Relapsed/Refractory Multiple Myeloma: Extended 4-Year Follow-Up and Analysis of Relative Progression-Free Survival From the Randomized ELOQUENT-2 Trial. Cancer (2018) 124(20):4032-43. doi: 10.1002/cncr.31680

275. Gormley NJ, Ko CW, Deisseroth A, Nie L, Kaminskas E, Kormanik N, et al. FDA Drug Approval: Elotuzumab in Combination With Lenalidomide and Dexamethasone for the Treatment of Relapsed or Refractory Multiple Myeloma. Clin Cancer Res Off J Am Assoc Cancer Res (2017) 23(22):675963. doi: 10.1158/1078-0432.CCR-16-2870

276. Wang Y, Sanchez L, Siegel DS, Wang ML. Elotuzumab for the Treatment of Multiple Myeloma. J Hematol Oncol J Hematol Oncol (2016) 9(1):55. doi: 10.1186/s13045-016-0284-z

277. Campbell KS, Cohen AD, Pazina T. Mechanisms of NK Cell Activation and Clinical Activity of the Therapeutic SLAMF7 Antibody, Elotuzumab in Multiple Myeloma. Front Immunol (2018) 9:2551. doi: 10.3389/ fimmu.2018.02551

278. Sun C, Fu B, Gao Y, Liao X, Sun R, Tian Z, et al. TGF- $\beta 1$ Down-Regulation of NKG2D/DAP10 and 2B4/SAP Expression on Human NK Cells Contributes to HBV Persistence. PloS Pathog (2012) 8(3):e1002594. doi: 10.1371/ journal.ppat.1002594
279. Castriconi R, Cantoni C, Della Chiesa M, Vitale M, Marcenaro E, Conte R, et al. Transforming Growth Factor Beta 1 Inhibits Expression of NKp30 and NKG2D Receptors: Consequences for the NK-Mediated Killing of Dendritic Cells. Proc Natl Acad Sci USA (2003) 100(7):4120-5. doi: 10.1073/pnas. 0730640100

280. McNerney ME, Lee KM, Kumar V. 2 b4 (CD244) is a non-MHC Binding Receptor With Multiple Functions on Natural Killer Cells and CD8+ T Cells. Mol Immunol (2005) 42(4):489-94. doi: 10.1016/j.molimm.2004.07.032

281. Garni-Wagner BA, Purohit A, Mathew PA, Bennett M, Kumar V. A Novel Function-Associated Molecule Related to non-MHC-Restricted Cytotoxicity Mediated by Activated Natural Killer Cells and T Cells. J Immunol Baltim Md 1950 (1993) 151(1):60-70.

282. Agresta L, Hoebe KHN, Janssen EM. The Emerging Role of CD244 Signaling in Immune Cells of the Tumor Microenvironment. Front Immunol (2018) 9:2809. doi: 10.3389/fimmu.2018.02809

283. Youn JI, Collazo M, Shalova IN, Biswas SK, Gabrilovich DI. Characterization of the Nature of Granulocytic Myeloid-Derived Suppressor Cells in TumorBearing Mice. J Leukoc Biol (2012) 91(1):167-81. doi: 10.1189/jlb.0311177

284. Jing Y, Ni Z, Wu J, Higgins L, Markowski TW, Kaufman DS, et al. Identification of an ADAM17 Cleavage Region in Human CD16 (Fcrriii) and the Engineering of a Non-Cleavable Version of the Receptor in NK Cells. PloS One (2015) 10(3):e0121788. doi: 10.1371/journal.pone.0121788

285. Mathiot C, Teillaud JL, Elmalek M, Mosseri V, Euller-Ziegler L, Daragon A, et al. Correlation Between Soluble Serum CD16 (Scd16) Levels and Disease Stage in Patients With Multiple Myeloma. J Clin Immunol (1993) 13(1):41-8. doi: 10.1007/BF00920634

286. Barrow AD, Martin CJ, Colonna M. The Natural Cytotoxicity Receptors in Health and Disease. Front Immunol (2019) 10:909. doi: 10.3389/fimmu. 2019.00909

287. Pazina T, Shemesh A, Brusilovsky M, Porgador A, Campbell KS. Regulation of the Functions of Natural Cytotoxicity Receptors by Interactions With Diverse Ligands and Alterations in Splice Variant Expression. Front Immunol (2017) 8:369. doi: 10.3389/fimmu.2017.00369

288. Glasner A, Levi A, Enk J, Isaacson B, Viukov S, Orlanski S, et al. NKp46 Receptor-Mediated Interferon- $\gamma$ Production by Natural Killer Cells Increases Fibronectin 1 to Alter Tumor Architecture and Control Metastasis. Immun (2018) 48(2):396-8. doi: 10.1016/j.immuni.2018.01.010

289. Glasner A, Ghadially H, Gur C, Stanietsky N, Tsukerman P, Enk J, et al. Recognition and Prevention of Tumor Metastasis by the NK Receptor Nkp46/NCR1. J Immunol Baltim Md 1950 (2012) 188(6):2509-15. doi: 10.4049/jimmunol.1102461

290. Han B, Mao FY, Zhao YL, Lv YP, Teng YS, Duan M, et al. Altered NKp30, NKp46, NKG2D, and DNAM-1 Expression on Circulating NK Cells Is Associated With Tumor Progression in Human Gastric Cancer. J Immunol Res (2018) 2018:6248590. doi: 10.1155/2018/6248590

291. Garcia-Iglesias T, Del Toro-Arreola A, Albarran-Somoza B, Del ToroArreola S, Sanchez-Hernandez PE, Ramirez-Dueñas MG, et al. Low NKp30, NKp46 and NKG2D Expression and Reduced Cytotoxic Activity on NK Cells in Cervical Cancer and Precursor Lesions. BMC Cancer (2009) 9:186. doi: 10.1186/1471-2407-9-186

292. Wu MR, Zhang T, DeMars LR, Sentman CL. B7H6-Specific Chimeric Antigen Receptors Lead to Tumor Elimination and Host Antitumor Immunity. Gene Ther (2015) 22(8):675-84. doi: 10.1038/gt.2015.29

293. Parodi M, Favoreel H, Candiano G, Gaggero S, Sivori S, Mingari MC, et al. NKp44-NKp44 Ligand Interactions in the Regulation of Natural Killer Cells and Other Innate Lymphoid Cells in Humans. Front Immunol (2019) 10:719. doi: $10.3389 /$ fimmu.2019.00719

294. Pogge von Strandmann E, Shatnyeva O, Hansen HP. NKp30 and its Ligands: Emerging Players in Tumor Immune Evasion From Natural Killer Cells. Ann Transl Med (2015) 3(20):314. doi: 10.3978/j.issn.2305-5839.2015.09.08

295. Schlecker E, Fiegler N, Arnold A, Altevogt P, Rose-John S, Moldenhauer G, et al. Metalloprotease-Mediated Tumor Cell Shedding of B7-H6, the Ligand of the Natural Killer Cell-Activating Receptor Nkp30. Cancer Res (2014) 74 (13):3429-40. doi: 10.1158/0008-5472.CAN-13-3017

296. Fiegler N, Textor S, Arnold A, Rölle A, Oehme I, Breuhahn K, et al. Downregulation of the Activating NKp30 Ligand B7-H6 by HDAC Inhibitors Impairs Tumor Cell Recognition by NK Cells. Blood (2013) 122 (5):684-93. doi: 10.1182/blood-2013-02-482513 
297. Wang W, Guo H, Geng J, Zheng X, Wei H, Sun R, et al. Tumor-Released Galectin-3, a Soluble Inhibitory Ligand of Human NKp30, Plays an Important Role in Tumor Escape From NK Cell Attack. J Biol Chem (2014) 289(48):33311-9. doi: 10.1074/jbc.M114.603464

298. Castriconi R, Dondero A, Bellora F, Moretta L, Castellano A, Locatelli F, et al. Neuroblastoma-Derived TGF- $\beta 1$ Modulates the Chemokine Receptor Repertoire of Human Resting NK Cells. J Immunol Baltim Md 1950 (2013) 190(10):5321-8. doi: 10.4049/jimmunol.1202693

299. Balsamo M, Manzini C, Pietra G, Raggi F, Blengio F, Mingari MC, et al. Hypoxia Downregulates the Expression of Activating Receptors Involved in NK-Cell-Mediated Target Cell Killing Without Affecting ADCC. Eur J Immunol (2013) 43(10):2756-64. doi: 10.1002/eji.201343448

300. Pinheiro PF, Justino GC, Marques MM. NKp30 - A Prospective Target for New Cancer Immunotherapy Strategies. Br J Pharmacol (2020) 177 (20):4563-80. doi: 10.1111/bph.15222

301. Viola D, Dona A, Caserta E, Troadec E, Besi F, McDonald T, et al. Daratumumab Induces Mechanisms of Immune Activation Through CD38+ NK Cell Targeting. Leukemia (2021) 35(1):189-200. doi: 10.1038/s41375-020-0810-4

302. Krejcik J, Casneuf T, Nijhof IS, Verbist B, Bald J, Plesner T, et al. Daratumumab Depletes CD38+ Immune Regulatory Cells, Promotes TCell Expansion, and Skews T-Cell Repertoire in Multiple Myeloma. Blood (2016) 128(3):384-94. doi: 10.1182/blood-2015-12-687749

303. Wang Y, Zhang Y, Hughes T, Zhang J, Caligiuri MA, Benson DM, et al. Fratricide of NK Cells in Daratumumab Therapy for Multiple Myeloma Overcome by Ex Vivo Expanded Autologous NK Cells. Clin Cancer Res Off J Am Assoc Cancer Res (2018) 24(16):4006-17. doi: 10.1158/1078-0432.CCR17-3117

304. Casneuf T, Adams HC, van de Donk NWCJ, Abraham Y, Bald J, Vanhoof G, et al. Deep Immune Profiling of Patients Treated With Lenalidomide and Dexamethasone With or Without Daratumumab. Leukemia (2021) 35 (2):573-84. doi: 10.1038/s41375-020-0855-4

305. Casneuf T, Xu XS, Adams HC, Axel AE, Chiu C, Khan I, et al. Effects of Daratumumab on Natural Killer Cells and Impact on Clinical Outcomes in Relapsed or Refractory Multiple Myeloma. Blood Adv (2017) 1(23):2105-14. doi: 10.1182/bloodadvances.2017006866

306. Zhu C, Song Z, Wang A, Srinivasan S, Yang G, Greco R, et al. Isatuximab Acts Through Fc-Dependent, Independent, and Direct Pathways to Kill Multiple Myeloma Cells. Front Immunol (2020) 11:1771. doi: 10.3389/ fimmu.2020.01771

307. Pazina T, James AM, MacFarlane AW, Bezman NA, Henning KA, Bee C, et al. The Anti-SLAMF7 Antibody Elotuzumab Mediates NK Cell Activation Through Both CD16-Dependent and -Independent Mechanisms. OncoImmunol (2017) 6(9):e1339853. doi: 10.1080/2162402X.2017.1339853

308. Yang G, Gao M, Zhang Y, Kong Y, Gao L, Tao Y, et al. Carfilzomib Enhances Natural Killer Cell-Mediated Lysis of Myeloma Linked With Decreasing Expression of HLA Class I. Oncotarget (2015) 6(29):26982-94. doi: 10.18632/ oncotarget.4831

309. Shi J, Tricot GJ, Garg TK, Malaviarachchi PA, Szmania SM, Kellum RE, et al. Bortezomib Down-Regulates the Cell-Surface Expression of HLA Class I and
Enhances Natural Killer Cell-Mediated Lysis of Myeloma. Blood (2008) 111 (3):1309-17. doi: 10.1182/blood-2007-03-078535

310. Pellom ST, Dudimah DF, Thounaojam MC, Sayers TJ, Shanker A. Modulatory Effects of Bortezomib on Host Immune Cell Functions. Immunother (2015) 7(9):1011-22. doi: 10.2217/imt.15.66

311. Holstein SA, McCarthy PL. Immunomodulatory Drugs in Multiple Myeloma: Mechanisms of Action and Clinical Experience. Drugs (2017) 77(5):505-20. doi: 10.1007/s40265-017-0689-1

312. Quach H, Ritchie D, Stewart AK, Neeson P, Harrison S, Smyth MJ, et al. Mechanism of Action of Immunomodulatory Drugs (IMiDS) in Multiple Myeloma. Leukemia (2010) 24(1):22-32. doi: 10.1038/leu.2009.236

313. Davies FE, Raje N, Hideshima T, Lentzsch S, Young G, Tai YT, et al. Thalidomide and Immunomodulatory Derivatives Augment Natural Killer Cell Cytotoxicity in Multiple Myeloma. Blood (2001) 98(1):210-6. doi: 10.1182/blood.v98.1.210

314. Hayashi T, Hideshima T, Akiyama M, Podar K, Yasui H, Raje N, et al. Molecular Mechanisms Whereby Immunomodulatory Drugs Activate Natural Killer Cells: Clinical Application. Br J Haematol (2005) 128 (2):192-203. doi: 10.1111/j.1365-2141.2004.05286.x

315. Besson L, Charrier E, Karlin L, Allatif O, Marçais A, Rouzaire P, et al. OneYear Follow-Up of Natural Killer Cell Activity in Multiple Myeloma Patients Treated With Adjuvant Lenalidomide Therapy. Front Immunol (2018) 9:704. doi: 10.3389/fimmu.2018.00704

316. Kini Bailur J, Mehta S, Zhang L, Neparidze N, Parker T, Bar N, et al. Changes in Bone Marrow Innate Lymphoid Cell Subsets in Monoclonal Gammopathy: Target for IMiD Therapy. Blood Adv (2017) 1(25):2343-7. doi: 10.1182/bloodadvances.2017012732

317. Krönke J, Udeshi ND, Narla A, Grauman P, Hurst SN, McConkey M, et al. Lenalidomide Causes Selective Degradation of IKZF1 and IKZF3 in Multiple Myeloma Cells. Science (2014) 343(6168):301-5. doi: 10.1126/science.1244851

Conflict of Interest: The authors declare that the research was conducted in the absence of any commercial or financial relationships that could be construed as a potential conflict of interest.

Publisher's Note: All claims expressed in this article are solely those of the authors and do not necessarily represent those of their affiliated organizations, or those of the publisher, the editors and the reviewers. Any product that may be evaluated in this article, or claim that may be made by its manufacturer, is not guaranteed or endorsed by the publisher.

Copyright (c) 2022 Venglar, Bago, Motais, Hajek and Jelinek. This is an open-access article distributed under the terms of the Creative Commons Attribution License (CC BY). The use, distribution or reproduction in other forums is permitted, provided the original author(s) and the copyright owner(s) are credited and that the original publication in this journal is cited, in accordance with accepted academic practice. No use, distribution or reproduction is permitted which does not comply with these terms. 